\title{
CircRNAs as potent biomarkers in ovarian cancer: a systematic scoping review
}

\author{
Zahra Foruzandeh ${ }^{1}$, Fatemeh Zeinali-Sehrig ${ }^{1}$, Kazem Nejati², Dara Rahmanpour ${ }^{1}$, Fariba Pashazadeh³, \\ Farhad Seif ${ }^{4}$ and Mohammad Reza Alivand ${ }^{1,3^{*}}$
}

\author{
${ }^{*}$ Correspondence: \\ alivandm@tbzmed. \\ ac.ir; mohammadreza_ \\ alivand@yahoo.com \\ 1 Department of Medical \\ Genetics, Faculty of Medicine, \\ Tabriz University of Medical \\ Sciences, Tabriz, Iran \\ Full list of author information \\ is available at the end of the \\ article
}

\begin{abstract}
More powerful prognostic and diagnostic tools are urgently needed for identifying and treating ovarian cancer $(\mathrm{OC})$, which is the most fatal malignancy in women in developed countries. Circular RNAs (circRNAs) are conservative and stable looped molecules that can regulate gene expression by competing with other endogenous microRNA sponges. This discovery provided new insight into novel methods for regulating genes that are involved in many disorders and cancers. This review focuses on the dysregulated expression of circRNAs as well as their diagnostic and prognostic values in OC. We found that studies have identified twenty-one downregulated circRNAs and fifty-seven upregulated ones. The results of these studies confirm that circRNAs might be potent biomarkers with diagnostic, prognostic and therapeutic target value for OC. We also consider the connection between circRNAs and OC cell proliferation, apoptosis, metastasis, and chemotherapy resistance and sensitivity.
\end{abstract}

Keywords: Circular RNA (CircRNA), Ovarian cancer (OC)

\section{Introduction}

Ovarian cancer (OC) is the most fatal malignancy among women [1]. One in 70 will develop OC and its incidence rate based on standard age (ASR) is 66 per 1,000,000 (GLOBOCAN 2020) [2]. One in 100 women will die of the disease and the ASR of mortality is 39 per $1,000,000$. OC accounts for $2.5 \%$ of all malignancies in women. Furthermore, $5 \%$ of deaths are due to the malignancy's asymptomatic progression and low survival rates, which are mostly due to late stage-diagnosis $[1,3]$.

The incomplete understanding of the genetic alterations and molecular pathways of OC means treatments cannot be properly targeted. Thus, despite the relatively rapid development of diagnostic and therapeutic techniques, the prognosis for patients with OC is still unsatisfactory. Elucidating its pathogenesis could reveal novel and promising biomarkers and targeted therapy sites $[4,5]$.

Non-coding RNAs (ncRNAs) comprise more than $98 \%$ of the human genome. They are transcribed from DNA without being translated into a protein and play essential roles in gene translation and regulation [6]. Importantly, many studies have demonstrated author(s) and the source, provide a link to the Creative Commons licence, and indicate if changes were made. The images or other third party material in this article are included in the article's Creative Commons licence, unless indicated otherwise in a credit line to the material. If material is not included in the article's Creative Commons licence and your intended use is not permitted by statutory regulation or exceeds the permitted use, you will need to obtain permission directly from the copyright holder. To view a copy of this licence, visit http:// creativecommons.org/licenses/by/4.0/. 
the role of ncRNAs in the early stages of tumor development, with links to cell growth, metastasis, apoptosis, and invasion [7, 8].

Circular RNA (circRNA), a large class of non-coding regulatory RNA, was first discovered in $1976[9,10]$. More than 30,000 circRNAs have already been discovered in human tissues [11]. They appear as circular genomes and exist in all kingdoms of life ranging from archaea to humans [12]. Most are expressed from protein-coding genes derived from single or multiple exons and are produced by back-splicing, a process that occurs in a reversed orientation. In other words, a downstream $5^{\prime}$-splice site is linked to an upstream $3^{\prime}$-splice site to produce a circRNA [13-15]. In recent years, circRNAs have been shown to be associated with various human disorders. Some have an important role in tumor onset and the progression of cancer. Genomic analysis shows a powerful presence of circRNA in many cancerous cell types [16-19]. Traits seen in these cancers are all present in OC. The potential roles of circRNAs in the pathogenesis of many human cancers have been confirmed through extensive studies conducted with novel extranuclear enrichment tools and next-generation sequencing (NGS), bioinformatics and microarray analyses, then validated for OC using quantitative real-time PCR with various primers [20]. Thus, it is known that many circRNAs are dysregulated in OC plasma, tissue and cell lines, and that they influence the development of OC by affecting cell proliferation, migration, invasion and apoptosis through absorption of miRNAs or impact on the cell cycle. Further research about circRNAs should focus on improving the potential of diagnosis and treatment of OC.

\section{Methods}

This study focuses on the identification and expression of dysregulated circRNAs. It also assesses their importance in the diagnosis of $\mathrm{OC}$ and estimation of patient prognosis. The study was performed in accordance with the JBI methodology for systematic scoping reviews [21]. The proposed review title has been registered in JBI (https://joannabrig gs.org/systematic-review-register) and its protocol has been registered on PRISMA flow diagram [22].

\section{Review question}

Question: What role do circRNA expression levels play in patients with ovarian cancer $(\mathrm{OC})$ ?

PCC

Participant type: Cisgender women with OC and related OC cell lines.

Concept: Circular RNA expression as biomarkers with prognostic and diagnostic functions.

Context: Not applicable and special.

\section{Search strategy}

Based on the reporting objects used in systematic scoping reviews, our searches were performed using Web of Science, PubMed, Embase and Scopus. The keywords were "circular RNA", "CircRNA", "Ovarian Cancer" and "OC", as well as other synonyms for 
circRNAs. The latest date of publication was April 2021 and the publication language was English. The search results were combined and de-duplicated.

\section{Study screening and inclusion}

EndNote X9 software was used to find and remove duplicates. References were arranged by number and exported to Microsoft Word for screening. The study process was summarized in a PRISMA flow diagram (Additional file 1).

\section{Study eligibility criteria}

The eligible studies were included with the following criteria: studies evaluating the expression of circRNA profiling in patients with OC; the association between OC cell lines or human samples and circRNA; the potential of circRNAs as biomarkers for early diagnosis; and the connection between chemotherapy-resistant metastatic OC and circRNAs. They had to be full-text articles in English. However, circRNA profiling research that uses cell lines or serum samples of patients with OC was also included. Those using other circRNA technologies, including NGS and PCR, those comparing OC tumor biopsies at various stages, and review articles were not encompassed.

\section{Data extraction}

Reviewers extracted data from qualified studies. We specify information related to study identification (author, year of publication, number and location of centers, and journal), the list of circRNAs and the study design being expressed differentially. Related supplementary information, including samples or cell lines, the related mRNA, and their expressions, functions and potential targets were extracted from relevant online databases, including Circad, CircNet, CircBase, and PubMed (Table 1). The limitations of our study were that most of the included articles had incomplete demographic information, e.g., the stages and grades of $\mathrm{OC}$ were not given.

\section{Data synthesis}

We extracted 487 articles from Web of Science, PubMed, Embase and Scopus. The results were merged and de-duplicated. After removing irrelevant articles, 78 abstracts were reviewed. The selection procedure is shown in the flowchart in Fig. 1. Data were organized based on circRNA name, targeted mRNA and its role in tumorigenesis (Table 2).

Table 1 CircRNA research databases

\begin{tabular}{ll}
\hline Name & URL \\
\hline Circad & http://clingen.igib.res.in/circad/index.html \\
CircNet & http://circnet.mbc.nctu.edu.tw \\
CircBase & http://www.circbase.org \\
PubMed & https://pubmed.ncbi.nlm.nih.gov \\
\hline
\end{tabular}


Records idenfied through database searching: Web of Science (N: 141), PubMed (N: 125), Embase (N: 106) and Scopus (N: 115)

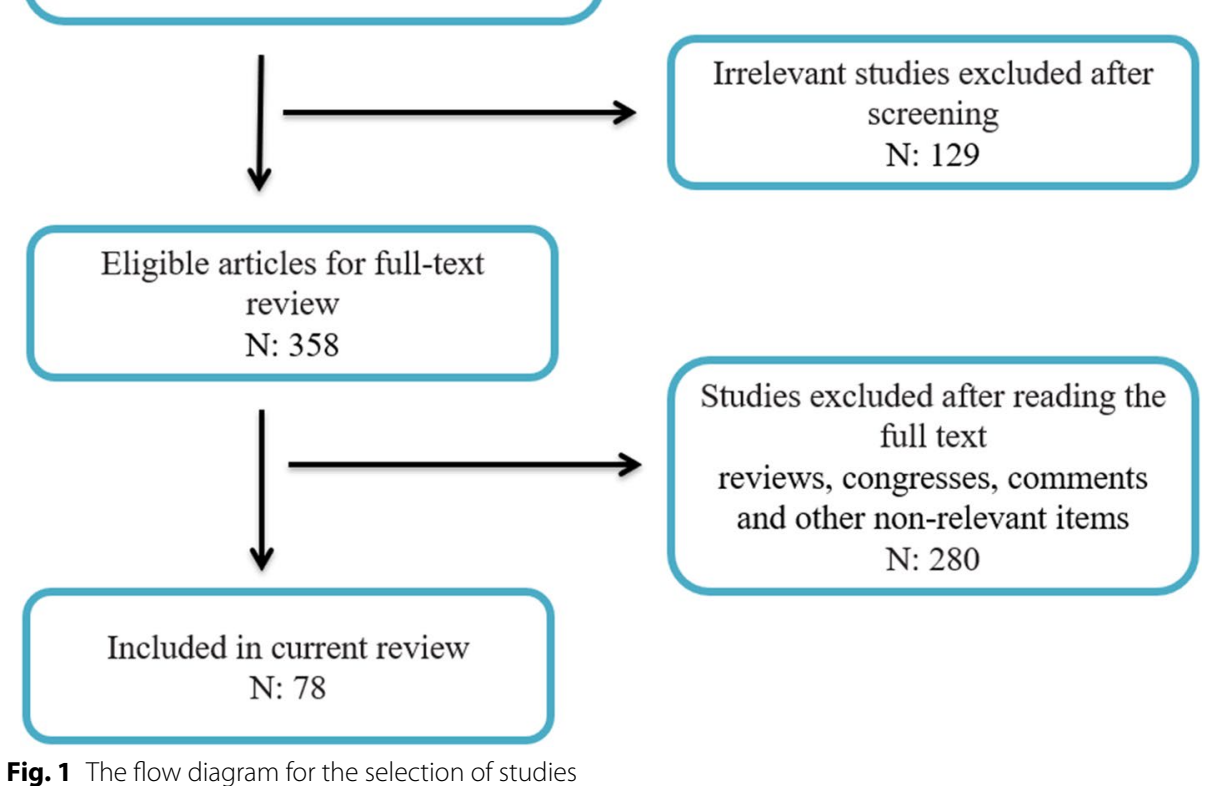

Fig. 1 The flow diagram for the selection of studies

\section{Discussion}

As with other non-coding RNAs (ncRNAs), circRNAs can adjust gene expression by sponging protein or RNA. The most-reported way involves regulating miRNA activity by acting as competition for endogenous miRNA sponge elements. This allows mRNA to escape from miRNA suppression post-transcriptionally [23]. The size of circRNAs ranges from several hundred to thousands of nucleotides that are produced from one to five exons. Since they do not have a free end, they are not prone to exonuclease degradation, making them very stable. They primarily reside in the cytoplasm or nucleus, originating from the precursor mRNA through back splicing of exons or introns (cytoplasmic) or simple splicing (nucleic) [24]. They can be categorized into three types based on differences in their genomes and main sequences: circular intronic RNAs (ciRNAs), exonic circRNAs (ecircRNAs), and exon-intron circRNAs (EIciRNAs) [25].

Notable characteristics of circRNAs include their prevalence and specificity [23, 24], high stability [26] and conservation [27]. They qualify as valuable clinical biomarkers or targets. Multiple biological roles for circRNAs have been explored, including:

1. CircRNAs are specific miRNA reservoirs or sponges.

2. CircRNAs interact with RNA-binding proteins (RBPs), which play a central function in transcription and translation of genes.

3. CircRNAs act as protein or peptide translators.

4. CircRNAs act as regulators of gene transcription and expression (Fig. 2). 
Table 2 Studies about dysregulated circRNAs in OC

\begin{tabular}{|c|c|c|c|c|c|}
\hline Circular RNAs & $\begin{array}{l}\text { Models or } \\
\text { sample types }\end{array}$ & $\begin{array}{l}\text { Regulation on } \\
\text { expression }\end{array}$ & $\begin{array}{l}\text { Targeted } \\
\text { miRNA }\end{array}$ & $\begin{array}{l}\text { Mechanism } \\
\text { or effects } \\
\text { on cancer } \\
\text { progression }\end{array}$ & References \\
\hline Circ-SETDB1 & $\begin{array}{l}\text { SOC patients } \\
\text { and healthy } \\
\text { volunteers }\end{array}$ & Upregulated & - & $\begin{array}{l}\text { It may act as a } \\
\text { novel biomarker } \\
\text { for finding SOC } \\
\text { improvement } \\
\text { and predict- } \\
\text { ing reaction to } \\
\text { platinum-tax- } \\
\text { ane-combined } \\
\text { chemotherapy } \\
\text { and recurrence } \\
\text { in SOC }\end{array}$ & Wang et al. [73] \\
\hline Circ-NFATC3 & OC cell lines & Upregulated & - & $\begin{array}{l}\text { It may play a } \\
\text { promising role } \\
\text { in increasing } \\
\text { cell proliferation, } \\
\text { migration and } \\
\text { invasion in OC }\end{array}$ & $\begin{array}{l}\text { Karedathet al. } \\
\text { [121] }\end{array}$ \\
\hline Circ-0015756 & $\begin{array}{l}\text { OC and adjacent } \\
\text { normal tissues } \\
\text { OC cell lines }\end{array}$ & Upregulated & miR-942-5p & $\begin{array}{l}\text { Suppressing } \\
\text { Circ-0015756 } \\
\text { inhibits OC pro- } \\
\text { motion through } \\
\text { the regulation } \\
\text { of miR-942-5p/ } \\
\text { CUL4B pathway } \\
\text { Circ-0015756 } \\
\text { may serve as a } \\
\text { novel therapeu- } \\
\text { tic target for OC }\end{array}$ & Du et al. [88] \\
\hline Circ-0002711 & $\begin{array}{l}\text { OC tissues and } \\
\text { cells } \\
\text { OC tissues and } \\
\text { cell lines }\end{array}$ & Upregulated & miR-1244 & $\begin{array}{l}\text { Circ-0002711/ } \\
\text { miR-1244/ } \\
\text { ROCK1 pathway } \\
\text { regulates tumor } \\
\text { growth in vivo }\end{array}$ & Xie et al. [89] \\
\hline Circ-0015326 & $\begin{array}{l}\text { Xenograft } \\
\text { tumors in vivo }\end{array}$ & Upregulated & miR-127-3p & $\begin{array}{l}\text { Circ-0015326 } \\
\text { facilizes OC } \\
\text { progres- } \\
\text { sion through } \\
\text { absorbing and } \\
\text { adjusting the } \\
\text { miR-127-3p/MYB } \\
\text { pathway } \\
\text { Circ-0015326 } \\
\text { may become a } \\
\text { promising thera- } \\
\text { peutic target } \\
\text { for OC }\end{array}$ & Zhang et al. [90] \\
\hline Circ-0025033 & $\begin{array}{l}\text { OC tissues and } \\
\text { cells }\end{array}$ & Upregulated & miR-330-5p & $\begin{array}{l}\text { MiR-330-5p } \\
\text { acts as a tumor } \\
\text { suppressor in OC } \\
\text { through target- } \\
\text { ing KLK4 } \\
\text { Circ-0025033 } \\
\text { may be a candi- } \\
\text { date in diagnosis } \\
\text { and therapeutic } \\
\text { target in OC }\end{array}$ & Cheng et al. [93] \\
\hline
\end{tabular}


Table 2 (continued)

\begin{tabular}{|c|c|c|c|c|c|}
\hline Circular RNAs & $\begin{array}{l}\text { Models or } \\
\text { sample types }\end{array}$ & $\begin{array}{l}\text { Regulation on } \\
\text { expression }\end{array}$ & $\begin{array}{l}\text { Targeted } \\
\text { miRNA }\end{array}$ & $\begin{array}{l}\text { Mechanism } \\
\text { or effects } \\
\text { on cancer } \\
\text { progression }\end{array}$ & References \\
\hline Circ-0025033 & $\begin{array}{l}\text { OC tissues and } \\
\text { cells }\end{array}$ & Upregulated & miR-184 & $\begin{array}{l}\text { Circ-0025033 } \\
\text { accelerates the } \\
\text { progression of } \\
\text { OC through } \\
\text { regulating LSM4 } \\
\text { expression by } \\
\text { absorbing miR- } \\
184 \\
\text { It provides a } \\
\text { new therapeutic } \\
\text { strategy for OC }\end{array}$ & $\begin{array}{l}\text { Hou and Zhang } \\
\text { [92] }\end{array}$ \\
\hline Circ-MUC16 & $\begin{array}{l}\text { EOC tissues and } \\
\text { healthy ovarian } \\
\text { tissues } \\
\text { Cell lines }\end{array}$ & Upregulated & miR-199a & $\begin{array}{l}\text { Circ-MUC16 } \\
\text { promotes } \\
\text { autophagy of } \\
\text { EOC through } \\
\text { absorbing miR- } \\
\text { 199a and regula- } \\
\text { tion of ATG13 }\end{array}$ & Gan et al. [76] \\
\hline Circ-KRT7 & OC cell lines & Upregulated & miR-29a-3p & $\begin{array}{l}\text { Circ-KRT7-miR- } \\
\text { 29a-3p-COL1A1 } \\
\text { pathway } \\
\text { increases } \\
\text { tumorigenesis } \\
\text { and promoting } \\
\text { cell proliferation } \\
\text { in OC }\end{array}$ & An et al. [139] \\
\hline Circ-0072995 & $\begin{array}{l}\text { EOC tissues and } \\
\text { cell lines }\end{array}$ & Upregulated & miR-147a & $\begin{array}{l}\text { A novel } \\
\text { diagnostic and } \\
\text { therapeutic bio- } \\
\text { marker in OC } \\
\text { It Enhances the } \\
\text { progression of } \\
\text { EOC via modu- } \\
\text { lating miR-147a/ } \\
\text { CDK6 pathway }\end{array}$ & Ding et al. [31] \\
\hline Circ-FGFR3 & $\begin{array}{l}\text { OC tissues and } \\
\text { their adjacent } \\
\text { normal tissues }\end{array}$ & Upregulated & miR-29a-3p & $\begin{array}{l}\text { Regulating EMT } \\
\text { of OC through } \\
\text { miR-29a-3p/ } \\
\text { E2F1 pathway } \\
\text { Its overexpres- } \\
\text { sion relates to } \\
\text { poor prognosis } \\
\text { in OC patients }\end{array}$ & Zhou et al. [83] \\
\hline Circ-PGAM & $\begin{array}{l}\text { EOC tissues and } \\
\text { cell lines }\end{array}$ & Upregulated & miR-542-3p & $\begin{array}{l}\text { Circ-PGAM1 } \\
\text { accelerates } \\
\text { malignant pro- } \\
\text { gression of EOC } \\
\text { by modulation } \\
\text { of the miR- } \\
542-3 p / C D C 5 L / \\
\text { PEAK1 axis }\end{array}$ & Zhang et al. [90] \\
\hline
\end{tabular}


Table 2 (continued)

\begin{tabular}{|c|c|c|c|c|c|}
\hline Circular RNAs & $\begin{array}{l}\text { Models or } \\
\text { sample types }\end{array}$ & $\begin{array}{l}\text { Regulation on } \\
\text { expression }\end{array}$ & $\begin{array}{l}\text { Targeted } \\
\text { miRNA }\end{array}$ & $\begin{array}{l}\text { Mechanism } \\
\text { or effects } \\
\text { on cancer } \\
\text { progression }\end{array}$ & References \\
\hline Circ-ABCB10 & $\begin{array}{l}\text { EOC and } \\
\text { adjacent normal } \\
\text { tissues } \\
\text { EOC cell lines }\end{array}$ & Upregulated & $\begin{array}{l}\text { miR-1271 } \\
\text { miR-1252 } \\
\text { miR-203 }\end{array}$ & $\begin{array}{l}\text { Circ-ABCB10 } \\
\text { relates to } \\
\text { advanced } \\
\text { clinicopathologi- } \\
\text { cal features and } \\
\text { unfavorable } \\
\text { survival } \\
\text { It accelerates } \\
\text { proliferation and } \\
\text { reduce apop- } \\
\text { tosis through } \\
\text { absorb of miR- } \\
1271 \text {, miR-1252 } \\
\text { and miR-203 in } \\
\text { EOC }\end{array}$ & Chen et al. [79] \\
\hline Circ-ABCB10 & $\begin{array}{l}\text { EOC cells and } \\
\text { normal epithelial } \\
\text { ovarian cells }\end{array}$ & Upregulated & miR-1271 & $\begin{array}{l}\text { Circ-ABCB10 } \\
\text { expression is } \\
\text { associated with } \\
\text { weak differentia- } \\
\text { tion, progressive } \\
\text { FIGO stage, and } \\
\text { large tumor size } \\
\text { by guiding the } \\
\text { miR-1271-me- } \\
\text { diated Capn4/ } \\
\text { Wnt/ß-catenin } \\
\text { signaling path- } \\
\text { way }\end{array}$ & Lin et al. [84] \\
\hline Circ-HIPK3 & $\begin{array}{l}\text { EOC tumor } \\
\text { tissues and adja- } \\
\text { cent noncancer- } \\
\text { ous tissues }\end{array}$ & Upregulated & - & $\begin{array}{l}\text { Promoting } \\
\text { proliferation, } \\
\text { migration and } \\
\text { invasion and } \\
\text { inhibit apoptosis }\end{array}$ & Teng et al. [32] \\
\hline Circ-051239 & $\begin{array}{l}\text { EOC tissues } \\
\text { and exosomes } \\
\text { derived from } \\
\text { plasma and cells } \\
\text { Cell lines in vitro }\end{array}$ & Upregulated & miR-509-5p & $\begin{array}{l}\text { Superior } \\
\text { metastatic EOC } \\
\text { cells can admit } \\
\text { this potential to } \\
\text { lower meta- } \\
\text { static potential } \\
\text { through exoso- } \\
\text { mal Circ-051239, } \\
\text { generating } \\
\text { raised prolifera- } \\
\text { tive, migratory } \\
\text { and invasive } \\
\text { inclusions in } \\
\text { receptor cells }\end{array}$ & Ma et al. [44] \\
\hline Circ-EEF2 & $\begin{array}{l}\text { OC cell lines } \\
\text { and } \\
\text { In vivo tumor } \\
\text { xenograft }\end{array}$ & Upregulated & miR-6881-3p & $\begin{array}{l}\text { Circ-EEF2 } \\
\text { increasing } \\
\text { autophagy } \\
\text { through absorb- } \\
\text { ing miR-6881-3p } \\
\text { and ANXA2 in } \\
\text { EOC }\end{array}$ & Yong et al. [81] \\
\hline
\end{tabular}


Table 2 (continued)

\begin{tabular}{|c|c|c|c|c|c|}
\hline Circular RNAs & $\begin{array}{l}\text { Models or } \\
\text { sample types }\end{array}$ & $\begin{array}{l}\text { Regulation on } \\
\text { expression }\end{array}$ & $\begin{array}{l}\text { Targeted } \\
\text { miRNA }\end{array}$ & $\begin{array}{l}\text { Mechanism } \\
\text { or effects } \\
\text { on cancer } \\
\text { progression }\end{array}$ & References \\
\hline Circ-RAB $11 \mathrm{FIP} 1$ & $\begin{array}{l}\text { EOC and normal } \\
\text { tissue }\end{array}$ & Upregulated & miR-129 & $\begin{array}{l}\text { Circ-RAB11FIP1 } \\
\text { increasing } \\
\text { autophagy of } \\
\text { OC via DSC1 } \\
\text { and miR-129 } \\
\text { and may serve } \\
\text { as a potential } \\
\text { biomarker for } \\
\text { EOC diagnosis } \\
\text { and targeted } \\
\text { therapy }\end{array}$ & Zhang et al. [82] \\
\hline Circ-KIF4A & OC tissues & Upregulated & miR-127 & $\begin{array}{l}\text { Promoting OC } \\
\text { progression via } \\
\text { miR-127/JAM3 } \\
\text { axis } \\
\text { A promising } \\
\text { novel biomarker } \\
\text { and therapeutic } \\
\text { target for OC }\end{array}$ & Sheng et al. [94] \\
\hline Circ-FAM53B & $\begin{array}{l}\text { OC specimens } \\
\text { and cell lines }\end{array}$ & Upregulated & $\begin{array}{l}\text { miR-646 } \\
\text { miR-647 }\end{array}$ & $\begin{array}{l}\text { Contributing } \\
\text { to oncogenesis } \\
\text { through spong- } \\
\text { ing miR-646 and } \\
\text { miR-647 leading } \\
\text { proliferation, } \\
\text { migration, and } \\
\text { invasion in OC }\end{array}$ & Sun et al. [85] \\
\hline Circ-Foxp1 & $\begin{array}{l}\text { Serum samples } \\
\text { from EOC } \\
\text { patients and } \\
\text { healthy people }\end{array}$ & Upregulated & $\begin{array}{l}\text { miR-22 } \\
\text { miR-150-3p }\end{array}$ & $\begin{array}{l}\text { Upregulated } \\
\text { circulating } \\
\text { exosomal } \\
\text { Circ-Foxp1 is a } \\
\text { self-determining } \\
\text { prognosis of } \\
\text { survival rate and } \\
\text { drug resistance } \\
\text { in EOC patients } \\
\text { and can use as a } \\
\text { novel biomarker } \\
\text { and possible } \\
\text { therapeutic } \\
\text { target for EOC }\end{array}$ & Luo and Gui [107] \\
\hline Circ-S-7 & $\begin{array}{l}\text { OC and normal } \\
\text { adjacent tissues }\end{array}$ & Upregulated & miR-641 & $\begin{array}{l}\text { Circ-S-7 pro- } \\
\text { motes OC EMT } \\
\text { by mediating } \\
\text { miR-641 to } \\
\text { up-regulate } \\
\text { ZEB1 and MDM2 } \\
\text { pathways }\end{array}$ & Luo and Gui [107] \\
\hline Circ-EPSTI1 & $\begin{array}{l}\text { OC tissues and } \\
\text { cell lines }\end{array}$ & Upregulated & miR-942 & $\begin{array}{l}\text { Circ-EPSTI1 } \\
\text { adjusts OC } \\
\text { promotion } \\
\text { through decoy- } \\
\text { ing miR-942 } \\
\text { And can be } \\
\text { serve as a } \\
\text { biomarker and } \\
\text { therapeutic } \\
\text { target in OC }\end{array}$ & Xie et al. [89] \\
\hline
\end{tabular}


Table 2 (continued)

\begin{tabular}{|c|c|c|c|c|c|}
\hline Circular RNAs & $\begin{array}{l}\text { Models or } \\
\text { sample types }\end{array}$ & $\begin{array}{l}\text { Regulation on } \\
\text { expression }\end{array}$ & $\begin{array}{l}\text { Targeted } \\
\text { miRNA }\end{array}$ & $\begin{array}{l}\text { Mechanism } \\
\text { or effects } \\
\text { on cancer } \\
\text { progression }\end{array}$ & References \\
\hline Circ-0061140 & OC cell lines & Upregulated & miR-370 & $\begin{array}{l}\text { Regulating cell } \\
\text { proliferation } \\
\text { in OC via } \\
\text { mediation of the } \\
\text { miR-370/ FOXM1 } \\
\text { pathway }\end{array}$ & Chen et al. [79] \\
\hline $\begin{array}{l}\text { VPS13C/Circ- } \\
001567\end{array}$ & $\begin{array}{l}\text { Tumor and adja- } \\
\text { cent tissues } \\
\text { OC cell lines }\end{array}$ & Upregulated & - & $\begin{array}{l}\text { Knocking down } \\
\text { of VPS13C/Circ- } \\
001567, \text { reduces } \\
\text { cell invasion, } \\
\text { cell cycle, cell } \\
\text { proliferation and } \\
\text { apoptosis ability }\end{array}$ & Bao et al. [66] \\
\hline Circ-VPS13C & OC cells & Upregulated & miR-145 & $\begin{array}{l}\text { Its Upregulation } \\
\text { in OC } \\
\text { Accelerates the } \\
\text { progression } \\
\text { of OC } \\
\text { Circ-VPS13C/ } \\
\text { miR-145/MEK/ } \\
\text { ERK axis sup- } \\
\text { pressed with } \\
\text { the treatment of } \\
\text { Propofol }\end{array}$ & Lu et al. [67] \\
\hline $\begin{array}{l}\text { RAD50/ Circ- } \\
00718\end{array}$ & $\begin{array}{l}\text { Tumor and } \\
\text { adjacent tissues } \\
\text { OC cell lines }\end{array}$ & Upregulated & - & $\begin{array}{l}\text { It takes part in } \\
\text { OC develop- } \\
\text { ment via adjust- } \\
\text { ing the biologi- } \\
\text { cal behaviors of } \\
\text { OC }\end{array}$ & Bao et al. [66] \\
\hline $\begin{array}{l}\text { SPECC1/ Circ- } \\
000013\end{array}$ & $\begin{array}{l}\text { Tumor and adja- } \\
\text { cent tissues } \\
\text { and OC cell lines }\end{array}$ & Upregulated & - & $\begin{array}{l}\text { It takes part in } \\
\text { OC develop- } \\
\text { ment via adjust- } \\
\text { ing the biologi- } \\
\text { cal behaviors of } \\
\text { OC }\end{array}$ & Bao et al. [66] \\
\hline Circ-CSPP1 & $\begin{array}{l}\text { OC tissues and } \\
\text { cell lines }\end{array}$ & Upregulated & miR-1236-3p & $\begin{array}{l}\text { Increasing ZEB1 } \\
\text { expression, } \\
\text { EMT related } \\
\text { markers, MMP-2 } \\
\text { and VEGFA } \\
\text { factors which } \\
\text { are belong to } \\
\text { tumorigenesis } \\
\text { Promoting cell } \\
\text { proliferation } \\
\text { and invasion by } \\
\text { sponging miR- } \\
1236-3 p\end{array}$ & Li et al. [61] \\
\hline Circ-PIP5K1A & $\begin{array}{l}\text { OC tissue and } \\
\text { cell lines }\end{array}$ & Upregulated & miR-661 & $\begin{array}{l}\text { It contributes } \\
\text { OC progression } \\
\text { through target- } \\
\text { ing the miR-661/ } \\
\text { IGFBP5 pathway } \\
\text { Associated with } \\
\text { poor prognosis }\end{array}$ & Sun et al. [77] \\
\hline
\end{tabular}


Table 2 (continued)

\begin{tabular}{|c|c|c|c|c|c|}
\hline Circular RNAs & $\begin{array}{l}\text { Models or } \\
\text { sample types }\end{array}$ & $\begin{array}{l}\text { Regulation on } \\
\text { expression }\end{array}$ & $\begin{array}{l}\text { Targeted } \\
\text { miRNA }\end{array}$ & $\begin{array}{l}\text { Mechanism } \\
\text { or effects } \\
\text { on cancer } \\
\text { progression }\end{array}$ & References \\
\hline Circ-CELSR1 & $\begin{array}{l}\text { OC tissue and } \\
\text { cell lines }\end{array}$ & Upregulated & miR-1252 & $\begin{array}{l}\text { Increasing of } \\
\text { Circ-CELSR1 } \\
\text { is associated } \\
\text { with enhanced } \\
\text { drug resistance } \\
\text { through Circ- } \\
\text { CELSR1/miR- } \\
\text { 1252/FOXR2 axis }\end{array}$ & Zhang et al. [74] \\
\hline Circ-CELSR1 & $\begin{array}{l}\text { OC tissue and } \\
\text { cells }\end{array}$ & Upregulated & miR-149-5p & $\begin{array}{l}\text { Reducing cell } \\
\text { sensitivity in to } \\
\text { drug resistance } \\
\text { by regulating } \\
\text { miR-149-5p/SIK2 } \\
\text { pathway }\end{array}$ & Wei et al. [99] \\
\hline Circ-GFRA1 & $\begin{array}{l}\text { OC tissues and } \\
\text { adjacent normal } \\
\text { tissues }\end{array}$ & Upregulated & miR-449a & $\begin{array}{l}\text { It acts as a novel } \\
\text { biomarker in } \\
\text { prognosis and } \\
\text { therapeutic } \\
\text { targets }\end{array}$ & Liu et al. [55] \\
\hline Circ-0013958 & $\begin{array}{l}\text { OC tissue and } \\
\text { cell lines }\end{array}$ & Upregulated & - & $\begin{array}{l}\text { Contributing } \\
\text { OC promotion } \\
\text { through affect- } \\
\text { ing EMT and } \\
\text { apoptosis } \\
\text { Circ-0013958 } \\
\text { may serve as a } \\
\text { novel diagnostic } \\
\text { and therapeutic } \\
\text { target in OC }\end{array}$ & Pei et al. [71] \\
\hline Circ-0005585 & $\begin{array}{l}\text { Normal ovarian } \\
\text { tissue } \\
\text { Benign OC } \\
\text { tissue } \\
\text { Primary and } \\
\text { metastatic EOC } \\
\text { tissue }\end{array}$ & Upregulated & $\begin{array}{l}\text { miR-23a } \\
\text { miR-23b } \\
\text { miR-15a } \\
\text { miR-15b } \\
\text { miR-16 }\end{array}$ & $\begin{array}{l}\text { ESRP1 overex- } \\
\text { pression was } \\
\text { regulated by } \\
\text { Circ-0005585 via } \\
\text { sponging miR- } \\
15 a \text {, miR-15b, } \\
\text { miR-16, and miR- } \\
\text { 23a, miR-23b, } \\
\text { which caused } \\
\text { inhibition of } \\
\text { cancer cells } \\
\text { migration and } \\
\text { metastasis }\end{array}$ & Deng et al. [58] \\
\hline Circ-102958 & $\begin{array}{l}\text { OC tissue and } \\
\text { cell lines }\end{array}$ & Upregulated & miR-1205 & $\begin{array}{l}\text { Circ-102958 } \\
\text { shows poor } \\
\text { prognosis and } \\
\text { promotes OC } \\
\text { progression } \\
\text { by miR-1205/ } \\
\text { SH2D3A path- } \\
\text { way }\end{array}$ & Wang et al. [59] \\
\hline
\end{tabular}


Table 2 (continued)

\begin{tabular}{|c|c|c|c|c|c|}
\hline Circular RNAs & $\begin{array}{l}\text { Models or } \\
\text { sample types }\end{array}$ & $\begin{array}{l}\text { Regulation on } \\
\text { expression }\end{array}$ & $\begin{array}{l}\text { Targeted } \\
\text { miRNA }\end{array}$ & $\begin{array}{l}\text { Mechanism } \\
\text { or effects } \\
\text { on cancer } \\
\text { progression }\end{array}$ & References \\
\hline Circ-MYLK & $\begin{array}{l}\text { tumor tissue } \\
\text { specimens and } \\
\text { paracancerous } \\
\text { normal ones }\end{array}$ & Upregulated & miR-652 & $\begin{array}{l}\text { Developing } \\
\text { malignancy } \\
\text { progression } \\
\text { of OC through } \\
\text { absorbing miR- } \\
652 \\
\text { associating with } \\
\text { pathological } \\
\text { staging } \\
\text { and poor } \\
\text { prognosis in OC } \\
\text { patients }\end{array}$ & Zhao et al. [60] \\
\hline Circ-PUM1 & $\begin{array}{l}\text { OC tissues } \\
\text { Normal tissues } \\
\text { Cell lines }\end{array}$ & Upregulated & $\begin{array}{l}\text { miR-615-5p } \\
\text { miR-6753-5p }\end{array}$ & $\begin{array}{l}\text { It acts as a } \\
\text { cancer derive } \\
\text { exosome } \\
\text { Promoting OC } \\
\text { proliferation and } \\
\text { migration }\end{array}$ & Guan et al. [72] \\
\hline Circ-RhoC & $\begin{array}{l}\text { OC tissues } \\
\text { Normal tissues } \\
\text { Cell lines }\end{array}$ & Upregulated & miR-302e & $\begin{array}{l}\text { Accelerating } \\
\text { tumorigenic- } \\
\text { ity via positive } \\
\text { regulation of } \\
\text { miR-302e/NEGFA } \\
\text { axis }\end{array}$ & Wang et al. [59] \\
\hline Circ-0000714 & $\begin{array}{l}\text { OC cells } \\
\text { Cell lines }\end{array}$ & Upregulated & miR-370-3p & $\begin{array}{l}\text { Controlling } \\
\text { and Regulating } \\
\text { RAB17/CDK6/ } \\
\text { RB axis } \\
\text { which progress } \\
\text { in the malig- } \\
\text { nancy of the } \\
\text { paclitaxel-resist- } \\
\text { ant OC cells }\end{array}$ & Guo et al. [100] \\
\hline Circ-TNPO3 & $\begin{array}{l}\text { OC samples } \\
\text { and correlated } \\
\text { with PTX resist- } \\
\text { ance }\end{array}$ & Upregulated & miR-1299 & $\begin{array}{l}\text { It plays a funda- } \\
\text { mental role in } \\
\text { the chemore- } \\
\text { sistance and } \\
\text { tumorigenesis } \\
\text { of OC through } \\
\text { upregulating } \\
\text { NEK2 expression }\end{array}$ & Xia et al. [101] \\
\hline Circ-NRIP1 & $\begin{array}{l}\text { Tumor xenograft } \\
\text { models }\end{array}$ & Upregulated & miR-211-5p & $\begin{array}{l}\text { It increasingly } \\
\text { expresses in } \\
\text { PTX-resistant OC } \\
\text { tissues and cells } \\
\text { Suppressing } \\
\text { of Circ-NRIP, } \\
\text { inhibited the } \\
\text { PTX resistance } \\
\text { in OC through } \\
\text { modulating the } \\
\text { miR-211-5p/ } \\
\text { HOXC8 pathway } \\
\text { It may act as a } \\
\text { prominent novel } \\
\text { target in resist- } \\
\text { ance therapy }\end{array}$ & Li et al. [102] \\
\hline Circ-UBAP2 & $\begin{array}{l}\text { OC tissues } \\
\text { and adjacent } \\
\text { normal tissues }\end{array}$ & Upregulated & miR-144 & $\begin{array}{l}\text { Promoting OC } \\
\text { progression via } \\
\text { sponging miR- } \\
144\end{array}$ & Sheng et al. [94] \\
\hline
\end{tabular}


Table 2 (continued)

\begin{tabular}{|c|c|c|c|c|c|}
\hline Circular RNAs & $\begin{array}{l}\text { Models or } \\
\text { sample types }\end{array}$ & $\begin{array}{l}\text { Regulation on } \\
\text { expression }\end{array}$ & $\begin{array}{l}\text { Targeted } \\
\text { miRNA }\end{array}$ & $\begin{array}{l}\text { Mechanism } \\
\text { or effects } \\
\text { on cancer } \\
\text { progression }\end{array}$ & References \\
\hline Circ-UBAP2 & $\begin{array}{l}\text { OC tissues and } \\
\text { cell lines }\end{array}$ & Upregulated & miR-382-5p & $\begin{array}{l}\text { Promoting } \\
\text { proliferation, } \\
\text { migration and } \\
\text { invasion and } \\
\text { inhibit apoptosis }\end{array}$ & Xu et al. [95] \\
\hline Circ-0001068 & $\begin{array}{l}\text { OC patients } \\
\text { and healthy } \\
\text { volunteers }\end{array}$ & Upregulated & miR-28-5p & $\begin{array}{l}\text { Circ-0001068 } \\
\text { was higher in } \\
\text { OC patients than } \\
\text { healthy ones } \\
\text { Play as a promi- } \\
\text { nent noninva- } \\
\text { sive biomarker } \\
\text { and aim for the } \\
\text { diagnosis and } \\
\text { therapeutic } \\
\text { targets in OC }\end{array}$ & Wang et al. [106] \\
\hline Circ-NOLC1 & $\begin{array}{l}\text { OC tissues } \\
\text { Normal tissues } \\
\text { Cell lines }\end{array}$ & Upregulated & $\begin{array}{l}\text { miR-326-5p } \\
\text { miR-330 } \\
\text { miR-370 } \\
\text { miR-9-5p }\end{array}$ & $\begin{array}{l}\text { Increasing cell } \\
\text { growth, migra- } \\
\text { tion, invasion, } \\
\text { and playing an } \\
\text { oncogenic role } \\
\text { by attaching } \\
\text { ESPR1, RhoA, } \\
\text { and modulating } \\
\text { CDK1 levels }\end{array}$ & Chen et al. [108] \\
\hline Circ-PVT1 & $\begin{array}{l}\text { EOC cell lines } \\
\text { and Normal } \\
\text { control cells }\end{array}$ & Upregulated & miR-149 & $\begin{array}{l}\text { Accelerating cell } \\
\text { proliferation } \\
\text { hindering } \\
\text { apoptosis }\end{array}$ & Sun et al. [85] \\
\hline Circ-PVT1 & $\begin{array}{l}\text { OC tissue and } \\
\text { normal tissue }\end{array}$ & Upregulated & miR-149-5p & $\begin{array}{l}\text { Increasing of } \\
\text { PVT1 levels } \\
\text { causes shorter } \\
\text { survival rate in } \\
\text { OC patients } \\
\text { Increasing } \\
\text { FOXM1 level } \\
\text { through binding } \\
\text { to miR-149-5p } \\
\text { Causing OC cell } \\
\text { viability and } \\
\text { migration }\end{array}$ & Li et al. [86] \\
\hline Circ-ASH2L & $\begin{array}{l}\text { OC cells in vitro } \\
\text { Tumor xeno- } \\
\text { grafts in vivo }\end{array}$ & Upregulated & miR-665 & $\begin{array}{l}\text { Acting as a } \\
\text { serious role in } \\
\text { adjusting OC cell } \\
\text { tumorigenesis, } \\
\text { lymphangiogen- } \\
\text { esis and angio- } \\
\text { genesis by the } \\
\text { miR-665NEGFA } \\
\text { pathway } \\
\text { It is a thinkable } \\
\text { candidate for } \\
\text { therapeutic } \\
\text { targets in OC }\end{array}$ & Chen et al. [79] \\
\hline Circ-0051240 & $\begin{array}{l}\text { OC and } \\
\text { correspond- } \\
\text { ing adjacent } \\
\text { non-cancerous } \\
\text { tissues }\end{array}$ & Upregulated & miR-637 & $\begin{array}{l}\text { Boosting cell } \\
\text { proliferation, } \\
\text { migration and } \\
\text { invasion in OC } \\
\text { by miR- } 637 / K L K 4 \\
\text { pathway }\end{array}$ & Zhang et al. [82] \\
\hline
\end{tabular}


Table 2 (continued)

\begin{tabular}{|c|c|c|c|c|c|}
\hline Circular RNAs & $\begin{array}{l}\text { Models or } \\
\text { sample types }\end{array}$ & $\begin{array}{l}\text { Regulation on } \\
\text { expression }\end{array}$ & $\begin{array}{l}\text { Targeted } \\
\text { miRNA }\end{array}$ & $\begin{array}{l}\text { Mechanism } \\
\text { or effects } \\
\text { on cancer } \\
\text { progression }\end{array}$ & References \\
\hline Circ-SMAD7 & $\begin{array}{l}\text { OC cells and } \\
\text { tissue }\end{array}$ & Upregulated & miR-630 & $\begin{array}{l}\text { Circ-SMAD7/ } \\
\text { miR-630/KLF axis } \\
\text { causing onco- } \\
\text { genic behavior } \\
\text { in OC }\end{array}$ & Zhao et al. [109] \\
\hline Circ_0026123 & $\begin{array}{l}\text { OC cell lines and } \\
\text { tissues }\end{array}$ & Upregulated & miR-124-3p & $\begin{array}{l}\text { Increasing OC } \\
\text { cells metastasis } \\
\text { and prolif- } \\
\text { eration via the } \\
\text { miR-124-3p/ } \\
\text { EZH2 axis }\end{array}$ & Yang et al. [25] \\
\hline Circ-WHSC1 & $\begin{array}{l}\text { normal ovaries } \\
\text { and } \\
\text { OC tissues }\end{array}$ & Upregulated & $\begin{array}{l}\text { miR-145 } \\
\text { miR-1182 }\end{array}$ & $\begin{array}{l}\text { Increasing } \\
\text { expression of } \\
\text { Circ-WHSC1 in } \\
\text { OC promotes } \\
\text { tumorigenesis } \\
\text { via modulation } \\
\text { of miR-145 and } \\
\text { miR-1182 }\end{array}$ & Zong et al. [64] \\
\hline Circ-0009910 & $\begin{array}{l}\text { OC tissues } \\
\text { Normal ovarian } \\
\text { tissues } \\
\text { OC cell lines }\end{array}$ & Upregulated & miR-145 & $\begin{array}{l}\text { Circ-0009910, } \\
\text { representing } \\
\text { poor prognosis } \\
\text { in OC cells } \\
\text { Inducing } \\
\text { proliferation and } \\
\text { motility } \\
\text { through } \\
\text { suppressing } \\
\text { miR-145 }\end{array}$ & Li et al. [65] \\
\hline $\begin{array}{l}\text { Circ-0002711 } \\
\text { Circ-0001756 }\end{array}$ & $\begin{array}{l}\text { OC patient } \\
\text { serum }\end{array}$ & Upregulated & - & $\begin{array}{l}\text { These CircRNAs } \\
\text { are presum- } \\
\text { ably related to } \\
\text { OC promotion, } \\
\text { and may be } \\
\text { promising novel } \\
\text { biomarkers }\end{array}$ & Wang et al. [73] \\
\hline Circ-0004390 & $\begin{array}{l}\text { OC tissue and } \\
\text { normal tissue }\end{array}$ & Upregulated & miR-198 & $\begin{array}{l}\text { Circ-0004390 } \\
\text { proliferation } \\
\text { through miR- } \\
\text { 198/MET path- } \\
\text { way, provides } \\
\text { a therapeutic } \\
\text { novel target } \\
\text { for OC }\end{array}$ & Xu et al. [57] \\
\hline Circ-1656 & $\begin{array}{l}\text { SOC tissues and } \\
\text { ovarian cell lines }\end{array}$ & Downregulated & - & $\begin{array}{l}\text { Acting as a } \\
\text { promising } \\
\text { biomarker } \\
\text { and significantly } \\
\text { associated with } \\
\text { SOC FIGO stage }\end{array}$ & Gao et al. [112] \\
\hline Circ-ITCH & $\begin{array}{l}\text { Tumor tissues } \\
\text { and paired } \\
\text { adjacent } \\
\text { tissues samples }\end{array}$ & Downregulated & - & $\begin{array}{l}\text { Suppressing } \\
\text { cells prolifera- } \\
\text { tion } \\
\text { Increases cells } \\
\text { apoptosis in EOC }\end{array}$ & Luo et al. [116] \\
\hline Circ-ITCH & $\begin{array}{l}\text { Human EOC cell } \\
\text { lines human } \\
\text { normal ovarian } \\
\text { epithelial cell } \\
\text { line }\end{array}$ & Downregulated & miR-10a-a & $\begin{array}{l}\text { Suppressing } \\
\text { cells prolifera- } \\
\text { tion } \\
\text { Increases cells } \\
\text { apoptosis in EOC }\end{array}$ & Luo et al. [116] \\
\hline
\end{tabular}


Table 2 (continued)

\begin{tabular}{|c|c|c|c|c|c|}
\hline Circular RNAs & $\begin{array}{l}\text { Models or } \\
\text { sample types }\end{array}$ & $\begin{array}{l}\text { Regulation on } \\
\text { expression }\end{array}$ & $\begin{array}{l}\text { Targeted } \\
\text { miRNA }\end{array}$ & $\begin{array}{l}\text { Mechanism } \\
\text { or effects } \\
\text { on cancer } \\
\text { progression }\end{array}$ & References \\
\hline Circ-ITCH & $\begin{array}{l}\text { OC tissues and } \\
\text { cell lines }\end{array}$ & Downregulated & miR-145 & $\begin{array}{l}\text { Suppressing the } \\
\text { malignancy of } \\
\text { OC cells through } \\
\text { the circ-ITCH- } \\
\text { miR-145-RASA1 } \\
\text { pathway }\end{array}$ & Hu et al. [113] \\
\hline Circ-ITCH & $\begin{array}{l}\text { OC tissues and } \\
\text { cell lines }\end{array}$ & Downregulated & HULC-IncRNA & $\begin{array}{l}\text { It's downregula- } \\
\text { tion of OC with } \\
\text { the mediate of } \\
\text { HULC InCRNA }\end{array}$ & Yan et al. [118] \\
\hline Circ-9119 & $\begin{array}{l}\text { OC tissues and } \\
\text { cell lines }\end{array}$ & Downregulated & miR-21 & $\begin{array}{l}\text { Regulating OC } \\
\text { cells proliferation } \\
\text { and apoptosis } \\
\text { through absorb- } \\
\text { ing miR- } 21 \text { and } \\
\text { targeting the } \\
\text { PTEN-Akt axis }\end{array}$ & Gong et al. [120] \\
\hline Circ-LARP4 & $\begin{array}{l}\text { OC tissue and } \\
\text { adjacent normal } \\
\text { tissue samples }\end{array}$ & Downregulated & - & $\begin{array}{l}\text { It's Low expres- } \\
\text { sion in OC } \\
\text { patients, makes } \\
\text { it a novel prog- } \\
\text { nostic biomarker }\end{array}$ & Zou et al. [122] \\
\hline CDR1as & $\begin{array}{l}\text { OC and EOC } \\
\text { tissues and cell } \\
\text { lines }\end{array}$ & Downregulated & miR-135b-5p & $\begin{array}{l}\text { By interme- } \\
\text { diation of miR- } \\
\text { 135-5p/ HIF1AN } \\
\text { pathway, sup- } \\
\text { pressing tumor } \\
\text { formation }\end{array}$ & Chen et al. [131] \\
\hline Cdr1as & $\begin{array}{l}\text { OC tissues and } \\
\text { cell lines }\end{array}$ & Downregulated & miR-1270 & $\begin{array}{l}\text { Reducing OC } \\
\text { cells drug } \\
\text { resistance by } \\
\text { upregulation } \\
\text { of SCAl and } \\
\text { downregulation } \\
\text { of miR-1270 }\end{array}$ & Zhao et al. [109] \\
\hline Circ-EXOC6B & $\begin{array}{l}\text { EOC specimens } \\
\text { and normal ovar- } \\
\text { ian tissues }\end{array}$ & Downregulated & - & $\begin{array}{l}\text { It can play a role } \\
\text { as a potential } \\
\text { prognostic } \\
\text { biomarkers in } \\
\text { patients with } \\
\text { EOC }\end{array}$ & Ning et al. [110] \\
\hline Circ-EXOC6B & $\begin{array}{l}\text { OC cells in vitro } \\
\text { OC cells in vivo }\end{array}$ & Downregulated & miR-376c-3p & $\begin{array}{l}\text { Increasing sen- } \\
\text { sitivity of drug } \\
\text { resistance of OC } \\
\text { cells } \\
\text { Decreasing } \\
\text { proliferation, } \\
\text { migration and } \\
\text { invasion of OC } \\
\text { cells through } \\
\text { miR-376c-3p/ } \\
\text { FOXO3 axis }\end{array}$ & Zheng et al. [114] \\
\hline Circ-EXOC6B & $\begin{array}{l}\text { Normal ovarian } \\
\text { epithelial cells } \\
\text { Human OC cell } \\
\text { lines }\end{array}$ & Downregulated & miR-421 & $\begin{array}{l}\text { Promising } \\
\text { target for the } \\
\text { treatment of OC } \\
\text { via sponging } \\
\text { miR-421 and } \\
\text { upregulating } \\
\text { RSU1 }\end{array}$ & Wang et al. [115] \\
\hline
\end{tabular}


Table 2 (continued)

\begin{tabular}{|c|c|c|c|c|c|}
\hline Circular RNAs & $\begin{array}{l}\text { Models or } \\
\text { sample types }\end{array}$ & $\begin{array}{l}\text { Regulation on } \\
\text { expression }\end{array}$ & $\begin{array}{l}\text { Targeted } \\
\text { miRNA }\end{array}$ & $\begin{array}{l}\text { Mechanism } \\
\text { or effects } \\
\text { on cancer } \\
\text { progression }\end{array}$ & References \\
\hline Circ-BNC2 & $\begin{array}{l}\text { OC tissue and } \\
\text { plasma samples }\end{array}$ & Downregulated & - & $\begin{array}{l}\text { Potential diag- } \\
\text { nostic biomark- } \\
\text { ers in patients } \\
\text { with EOC }\end{array}$ & Hu et al. [113] \\
\hline Circ-RHOBTB3 & $\begin{array}{l}\text { OC cells in vitro } \\
\text { OC cells in vivo }\end{array}$ & Downregulated & - & $\begin{array}{l}\text { Suppressing cell } \\
\text { proliferation and } \\
\text { metastasis } \\
\text { through PI3K } \\
\text { AKT signaling } \\
\text { pathway }\end{array}$ & Hu et al. [113] \\
\hline Circ-PLEKHM3 & $\begin{array}{l}\text { Primary OC/ } \\
\text { metastatic OC/ } \\
\text { normal ovarian } \\
\text { tissues/cell lines }\end{array}$ & Downregulated & miR-9 & $\begin{array}{l}\text { Targeting miR-9/ } \\
\text { BRCA1/DNAJB6/ } \\
\text { KLF4/AKT1 axis } \\
\text { Inactivates the } \\
\text { PI3K/AKT and } \\
\text { Wnt/catenin } \\
\text { pathways via } \\
\text { promoting } \\
\text { BRCA1, DNA- } \\
\text { JB6a, and KLF4 } \\
\text { expression by } \\
\text { sponging miR-9 }\end{array}$ & Zhang et al. [123] \\
\hline Circ-0007444 & $\begin{array}{l}\text { OC patients and } \\
\text { OC cells }\end{array}$ & Downregulated & miR-570-3p & $\begin{array}{l}\text { Circ-0007444 } \\
\text { suppressing } \\
\text { OC promotion } \\
\text { through the } \\
\text { miR-570-3p/ } \\
\text { PTEN pathway } \\
\text { It may serve as } \\
\text { a candidacy for } \\
\text { targeted therapy }\end{array}$ & Wu et al. [140] \\
\hline Circ-ANKRD12 & OC cell lines & Downregulated & miR-4768-5p & $\begin{array}{l}\text { Expression of } \\
\text { Circ-ANKRD12, } \\
\text { suppresses inva- } \\
\text { sive molecular } \\
\text { behaviors and } \\
\text { phenotypes } \\
\text { Circ-ANKRD12 } \\
\text { can act in a vari- } \\
\text { ous set of tasks } \\
\text { ranging from } \\
\text { cell cycle arrest, } \\
\text { tumor invasion } \\
\text { to immune } \\
\text { incorporation }\end{array}$ & $\begin{array}{l}\text { Karedath et al. } \\
\text { [121] }\end{array}$ \\
\hline Circ-0078607 & $\begin{array}{l}\text { OC tissues and } \\
\text { adjacent tissues } \\
\text { OC cell lines }\end{array}$ & Downregulated & miR-518a-5p & $\begin{array}{l}\text { Circ-0078607 } \\
\text { downregulation, } \\
\text { inhibits } \\
\text { OC progression } \\
\text { through miR- } \\
518 a-5 \text { p/Fas axis }\end{array}$ & Zhang et al. [123] \\
\hline Circ-0007874 & OC cell lines & Downregulated & miR-760 & $\begin{array}{l}\text { Circ-0007874 } \\
\text { downregulation, } \\
\text { inhibits } \\
\text { OC progres- } \\
\text { sion through } \\
\text { miR-760/SOCS3 } \\
\text { pathway }\end{array}$ & Li et al. [125] \\
\hline
\end{tabular}


Table 2 (continued)

\begin{tabular}{|c|c|c|c|c|c|}
\hline Circular RNAs & $\begin{array}{l}\text { Models or } \\
\text { sample types }\end{array}$ & $\begin{array}{l}\text { Regulation on } \\
\text { expression }\end{array}$ & $\begin{array}{l}\text { Targeted } \\
\text { miRNA }\end{array}$ & $\begin{array}{l}\text { Mechanism } \\
\text { or effects } \\
\text { on cancer } \\
\text { progression }\end{array}$ & References \\
\hline Circ-MTO1 & $\begin{array}{l}\text { OC tissues and } \\
\text { adjacent tissues } \\
\text { OC cell lines }\end{array}$ & Downregulated & miR-182-5p & $\begin{array}{l}\text { Circ-MTO1 sup- } \\
\text { presses the } \\
\text { proliferation and } \\
\text { invasion of OC } \\
\text { cells via the miR- } \\
182-5 \text { p/KLF15 } \\
\text { pathway }\end{array}$ & Wang et al. [115] \\
\hline Circ-100395 & OC tissues & Downregulated & miR-1228 & $\begin{array}{l}\text { Circ-100395 } \\
\text { suppresses cell } \\
\text { proliferation and } \\
\text { metastasis of OC } \\
\text { cells through } \\
\text { regulating the } \\
\text { miR-1228/p53/ } \\
\text { EMT pathway }\end{array}$ & Li et al. [125] \\
\hline
\end{tabular}

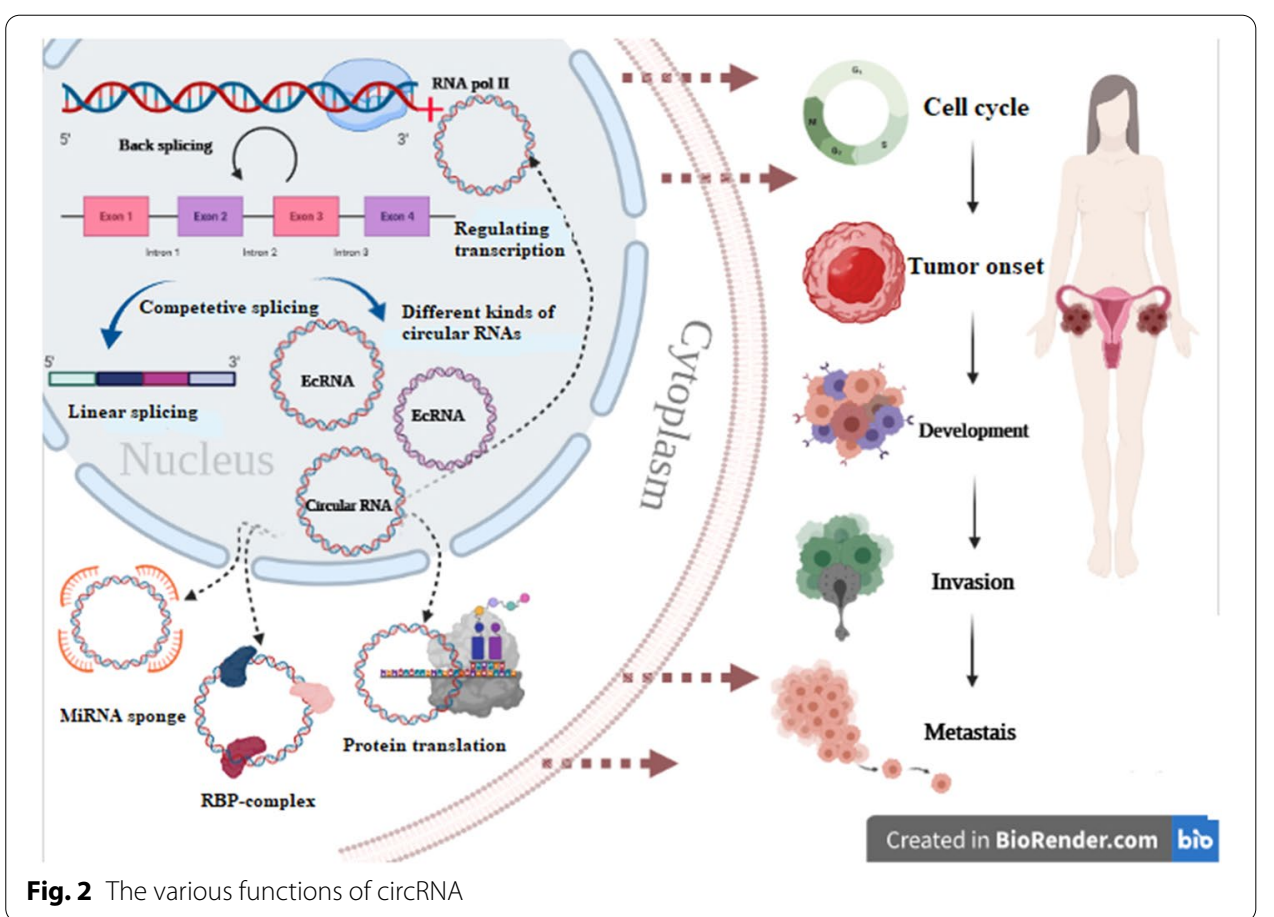

Considerable evidence has shown that circRNAs can affect the aggressive properties of tumors. For example, they compete with miRNAs, translate into proteins, act as miRNA reservoirs, and form fusion circRNAs (f-circRNAs) [28, 29]. Their unique characteristics, such as tissue-specificity, diversity and high stability could make them useful diagnostic markers, provided we develop a better understanding of their expression in cancer tissues [30].

According to the information we have about the importance of these circRNAs, their effect on various organs is not negligible. One of the organs that can be affected by these circRNAs is the ovaries. Ovaries play a fundamental role in the female reproductive 
system with the basic functions of producing oocytes under the stimulation of gonadotropic hormones secreted from the pituitary gland to guarantee the evolution of follicles, estrous cycles, and post-pregnancy hormonal levels. The risk factors for OC include age, a family history of the disease, and unremitting ovulation in carriers of the heredity mutation of BRCA1 [31]. The occurrence and progression of OC is a complicated process, encompassing multi-factor, multi-step and multi-gene regulation [32]. OC comprises a group of heterogeneous malignancies recognized via cell or site of origin, risk factors, pathological degree, prognosis, and treatment. It has three principal types: epithelial, germ cell, and sex-cord-stromal, with the latter two containing just about $5 \%$ of all OCs [33]. The most common malignancies amongst women of all ethnicities and groups are epithelial cancers, counting for $90 \%$ of all cases [34]. There are four primitive histological subgroups of epithelial ovarian cancer (EOC): serous, endometrioid, mucinous, and clear cell [35]. Serous tumors are classified into two categories: high-grade serous carcinomas (HGSC) or low-grade serous carcinomas (LGSC) [36].

Invasive therapies, such as surgery, and drug therapies have not sufficiently reduced OC mortality. Finding new biomarkers and targets may help with earlier diagnosis and more effective treatment. The relationships between circRNAs and OC have considerable potential because of their regulatory roles. It is known that abnormalities in the regulation of signaling pathways and cellular mechanisms cause cancer formation, progression, and metastasis. In the past few years, multiple studies have focused on differentially expressed circRNAs in OC, indicating that circRNAs could be therapeutic targets and novel biomarkers for this disease [37].

\section{CircRNAs in cancer}

Various internal and external factors are involved in cancer pathogenesis. Genetic and epigenetic factors are the main ones [38, 39]. Multiple recent studies have confirmed that circRNAs play a substantial role in the initiation and progression of various cancers, such as hepatic and renal carcinoma, and bladder, prostate, esophageal, breast, gastric and lung cancer [40-45]. Considerable evidence shows that these circRNAs function in a great number of cancers and play essential roles in their occurrence and development [46]. However, the results of studies on cancer cell lines and tissues indicate that circRNAs can be involved as oncogenes or tumor-suppressor genes [47, 48].

\section{CircRNAs and their roles in OC pathogenesis}

Ahmed et al. were the first to conduct an expression analysis on circRNAs in ovarian tumors. They found that a great number of circRNAs are differentially expressed in tumors [49]. They also examined the differential expression of circRNA and mRNA between primary and metastatic ovarian tumors. Because of the stability of circRNAs against exonuclease resistance [50], they could recognize the primary tumor from metastatic lesions. Many circRNAs have been identified as oncogenes by focusing on circRNA-miRNA sponging and recognizing the biological effects and regulatory networks involving the miRNAs and the subsequently targeted genes. Multiple circRNAs have an oncogenic pattern in $\mathrm{OC}$ since their upregulation boosts cell progression and tumor growth. Based on the most recent evidence from CircBase and Interactome analysis, circ-NFATC3, which is involved in ovarian cancer, can potentially adjust multiple 
biological operations: protein decoy, cell proliferation and motility, apoptosis, senescence, and cell responses to oxidative stress. It achieves its effects through post-transcriptional alignments, like cell translation, conservation and RNA alternative splicing, via sponging RBPs and microRNAs [51].

Multiple circRNAs, such as circ-0051240, circ-EPSTI1, circ-PIP5K1A and circGFRA1, cause malignant behavior of OC cells by acting as miRNA sponges [52-55]. circ-PIP5K1A becomes overexpressed when miR-661 is targeted. Circ-PIP5K1A is located on chromosome 1 . Silencing it markedly suppressed the ability of OC cells to proliferate and invade other tissues [54]. Xie et al. showed the remarkable upregulation of circ-EPSTI1 in OC cells and specimens in comparison with their adjacent non-tumor counterparts. Based on their observation, the inhibition of circ-EPSTI1 can suppress cancer cell proliferation and migration, which causes apoptosis in OC. This emphasizes the carcinogenic role of this circRNA [53].

Circ-UBAP2 promotes the expression of N-cadherin in OC cells by sponging miR-144 as well as exerting conservative effects on $\mathrm{OC}$ cell proliferation and invasion. Overexpression of miR-144 has a reverse effect on Circ-UBAP2 tumorigenesis [56]. Another study conducted on circ-UBAP2 showed that cell proliferation increases upon overexpression of circ-UBAP2 and cell apoptosis decreases via the miR-382-5p/PRPF8 pathway [57]. Deng et al. found that ESRP1 overexpression is regulated by circ-0005585 via sponging of miR-15a, miR-15b, miR-16, miR-23a and miR-23b, which inhibited cancer cell migration and metastasis through alternative splicing of two cytoskeleton-associated proteins: EPB41L5 and Rac1 [58].

Silencing circ-102958 significantly inhibits OC cell proliferation and invasion and its upregulation is associated with a poor prognosis in OC patients. It promotes OC cell proliferation and migration by increasing the expression of SH2D3A through influence on the activity of miR-1205 as a competing endogenous RNA (ceRNA) [59].

The circ-MYLK level in patients with OC has been found to be significantly higher in cancer tissues than that in adjacent ones. Circ-MYLK can be targeted by microRNA-652 [60]. Li et al. assessed the mechanism of another oncogenic circRNA, circ-0001806 (also named circ-CSPP1), which is located at position 13.2 on the long (q) arm of chromosome 8 and derived from centrosome/spindle pole-associated protein 1 gene. This circRNA was found to be upregulated in OC tumors and tumor margins. However, an increase in miR-1236-3p due to silencing circ-CSPP1 in OC cell lines, decreases ZEB1 expression at the RNA and protein levels [61].

Hsa-Circ-0026123 inhibits OC progression by mediating the miR-124-3p/EZH2 candidate biomarker for the diagnosis and therapeutic target of OC [62]. In 2019, researchers found circ-SMAD7 on chromosome 18 was upregulated and promoted tumorigenesis in $\mathrm{OC}$ cells. Using bioinformatics procedures, a tumor suppressor protein, Krüppel-like factor 6 (KLF6), was proven to be highly downregulated in OC tissues. Increased expression of circ-SMAD7 might result suppress KLF6, leading to tumor formation [63]. Microarray screening of circ-WHSC1, which is more highly expressed in OC cells than normal ones, revealed that the linkage of miR-1182 and miR0145 promotes tumor formation by increasing cell proliferation and metastasis in OC [64]. Circ0009910 is an oncogenic circRNA indicative of poor prognosis in patients with OC. It induces tumor growth via interaction with miR-145: together, they influence the JAK1/ 
STAT and NOTCH signaling pathway to accelerate proliferation and metastasis [65]. Bao et al. investigated VPS13C/hsa-circ-001567, RAD50/hsa-circ-00718 and SPECC1/ hsa-circ-000013 to establish their vital role in OC [66]. They found that the expression of these three circRNAs was markedly increased in tumor tissues in comparison with noncancerous samples. VPS13C/hsa-circ-001567 had the highest expression in the tumor tissues. Propofol has been used to control and tune tumor cell growth with the dualluciferase assay used to monitor the outcomes. Propofol treatment downregulated circVPS13C, suppressing the activation of the MEK/ERK signaling pathway via upregulation of miR-145 [67].

Multiple studies are showing that circRNAs are significant in EOC. Circ-PGAM1 was found to be an oncogenic circRNA in EOC tissues and cells by Zhang et al. They silenced it and showed inhibition of progression in EOC tissues and cells. A related miRNA, miR542-3p, was found to be downregulated in EOC tissues and cells. Its overexpression suppressed the formation of tumors in related tissues and cells [68].

As mentioned before, circRNAs have other functions and can play a crucial role in tumor cell proliferation, apoptosis, metastasis and invasion. Here are some of the studies that investigate possible mechanisms by which circRNAs take part in OC development. Chen et al. found high distribution of circ-ASH2L in the cytoplasm, where it competes with vascular endothelial growth factor A (VEGFA) to absorb miR-665. This evidence justifies the role of circ-ASH2L in tumorigenesis and angiogenesis via the miR-665/ VEGFA pathway [69]. The incidence of epithelial-mesenchymal transition (EMT) was noted as one of the factors of tumor metastasis. Circ-KRT7 increases EMT-related cell progression through sponging miR- 29a-3p in OC. This study suggests this biological role could be a factor for the diagnosis and treatment of OC [70]. Circ-0013958 also contributes to the development of OC: it shows high expression in OC cells and tissues, and it affects EMT and signaling pathways related to apoptosis. Although circ-0013958 inhibition can increase the amount of cell apoptosis, it can suppress OC cell growth, migration and metastasis in vitro [71].

There is a high expression of circ-PUM1 in normal ovarian tissues. There is also a direct relationship between its high expression and advanced stages of $\mathrm{OC}$ as defined using the FIGO scale from the International Federation of Gynecology and Obstetrics. Cell line-based studies revealed that circ-PUM1 increases cell invasiveness and proliferation by sponging miR-6753-5p and miR-615-5p to upregulate MMP2 and NF-kB expression. Guan et al. found that Circ-PUM1, on the one hand, causes rapid OC cell growth, invasion and metastasis, and on the other hand, by acting on the peritoneum, contributes to cancer metastasis via the formation of cancerous exosomes [72].

Many circRNAs, such as circ-RhoC, promote angiogenesis in OC. High expression of circ-RhoC promotes tumor formation and metastasis. However, this circRNAs sponging of miR-302 upregulates VEGFA expression, which is involved in metastasis and angiogenesis [73].

Zhang et al. discovered that one of the functions of circRNAs is to attenuate the inhibitory effects of miRNAs on protein translation by competing with them and interfering with target mRNAs. As an example, circ-S-7 has 74 conserved binding sites that can attach to the targeted miRNA. Meanwhile, it can also interact with miRNAs by attaching to argonaute proteins. Circ-S-7 expression is significantly higher in OC tissues and cells, 
indicating an association with the lymph node metastasis status, tumor node metastasis (TNM) classification of malignant tumor stages, and overall survivorship rates in patients with OC. Its silencing inhibited the growth and metastasis of OC cells [74].

Circ-NOLC1 is another circRNA that is more highly expressed in EOC tissues than in normal tissues and is positively related to the FIGO-defined stage. Its overexpression in cell lines is proven to increase cell growth, migration and invasion. It plays an oncogenic role by attacking to ESPR1 and RhoA, and by modulating CDK1 levels [75].

The next circRNA with diagnostic potential in EOC patient serum and tissues is circ0049116, which is generated from a cell surface-associated protein named mucin 16 . Increased expression of the circ-MUC16/miR-199a-5p axis positively correlates with the degree of tumorigenesis in EOC patients [76]. The expression levels of circ-FAM35b, circ-051239, circ-ABCB10, circ-0072995, circ-EEF2, circ-RAB11FIP1, circ-FGFR3, circNOLC1 and circ-PGAM1 correlate with diverse clinical and pathological traits of EOC $[68,75,77-83]$. To determine the potential role of the molecular mechanism of circFAM35B besides its prognostic ability in OC, a luciferase reporter gene assay and bioinformatics analysis were done. The results showed its overexpression correlated with proliferation, metastasis and prohibition of apoptosis in OC samples [77]. Superior metastatic EOC cells possess the capability to lower metastatic potential through exosomal circ-051239, leading to more proliferative, migratory and invasive inclusions in receptor cells [78].

Of all the circRNAs known to be involved in EOC, circ-ABCB10 is associated with the worst overall survival rate (OS). According to the in vitro experiments done by Chen et al., circ-ABCB10 showed negative regulation of miR-203, miR-1271 and miR-1252 in EOC cells as well as an association with increased cell proliferation and decreased apoptosis rate. Thus, circ-ABCB10 expression is associated with weak differentiation, progressive FIGO stages, and large tumor size. This is known to be due to its guiding of the mir1271-mediated Capn4/Wnt/ $\beta$-catenin signaling pathway $[79,84]$.

Circ-0072995 increases malignancy through its influence on the miR-147a/CDK6 axis. Circ-EEF2 and circ-RAB11FIP1 facilitate autophagy by sponging mir-6881-3p and miR-129 in EOC [80-82]. Another oncogenic circRNA affecting EOC is plasmacytoma variant translocation 1 (PVT1), which is an extremely dysregulated gene in malignancy and is reported to have an association with EOC oncogenesis [85]. Although circ-PVT1 increases cell proliferation, it decreases apoptosis by sponging miR-149. It is therefore a potential a treatment target in EOC [86]. The alteration of cell viability and drug resistance was found with the intervention of FOX transcription factors (FOXM1) with the involvement of the PTV1/miR-149-5p axis.

\section{Roles in clinical implications of $\mathrm{OC}$}

Some CircRNAs have potential as biomarkers because their abnormal regulation is associated with pathological and clinical outcomes in OC patients. In 2020, Wang et al. conducted a comprehensive study using the serum of patients with OC instead of tissue samples. Using bioinformatics analyses of data and studying miRNA-binding sites, they identified 5 important upregulated circRNAs: circ-0002711; Chr5:170610175-170632616+; circ-0001756; Chr4:147227078-147230127-; and Chr16:53,175091-53191453+. They all 
showed an association with dysregulation in $\mathrm{OC}$ and were considered potential diagnostic biomarkers [87].

Numerous studies have shown that circ-0015756, circ-0002711, hsa-circ-0015326, circ-0001068, circ-0025033 and circ-KIF4A are oncogenic circRNAs with diagnostic and prognostic value in OC [88-94]. Their function occurs through sponge of corresponding miRNAs. Circ-0015756 increases the progress of OC by sponging miR-942-5p and influencing the miR-942-5p/CUL4B axis [88]. Similarly, the circ-0002711/miR-1244/ ROCK1 and has-circ-0015326/miR-127-3p/MYB pathways are key players in OC with potential as therapeutic targets $[89,90]$. Outcomes from a larger cohort showed that circ-0001068/miR-28-5p in T cells induced PD1 expression, and this caused in T-cell exhaustion [91]. Circ-KIF4A and circ-0025033 promote OC progression by absorbing miR-127 and miR-184, respectively [92, 94]. In 2020, another study was conducted on circ-0025033 that confirmed its role in cell viability, invasion [93]. These alterations occur through the miR-330-5p/KLK4 axis. This regulatory mechanism confirms circ0025033 may be a prominent therapeutic target for OC.

Circ-0004390, which is derived from LPAR3 gene, is significantly upregulated in OC cells and tissues. Its knockdown can markedly reduce OC cell proliferation. By sponging miR-198, circ-0004390 increases cell proliferation to regulate the expression of hepatocyte growth factor receptor in OC cells. Xu et al. expressed that the level of circ-0004390 was closely related to the overall survivor level in patients with OC and found that it regulates OC proliferation via miR-198. The axis provides an important target in therapy [95].

One of the most valid and effective treatments for patients with cancer is chemotherapy. However, the chemical resistance resulting from the constant use of this method has gradually become a concern. In recent years, circRNAs have been considered significant targets and markers for the prognosis, diagnosis and treatment of many diseases, especially cancer [96]. In 2012, circ-0061140 was detected using luciferase reporter assays and RNA fluorescence in situ hybridization (FISH) technique and was analyzed using bioinformatic techniques. The results show the promotion of cell proliferation and metastasis in cell lines because of circ-0061140 sponging miR-370, which was followed by a decrease in FOXM expression [97]. In addition to circ-0061140, FOX transcription factors also cooperate with circ-CELSR1. Two separate molecular assay-based studies were conducted on circ-CELSR1 and its potential role in drug resistance (PTX-resistance) $[98,99]$. Circ-CELSR1 overexpression was determined in PTX-resistant cells and tissues. Using quantitative real-time PCR and microarray analyses, Zhang et al. found that circ-CELSR1 was associated with an aggressive OC phenotype and acted through sponging miR1252. Indeed, the circ-CELSR1/miR-1252/FOXR2 axis directly effects on paclitaxel-resistance (PTX) [98]. The next study on circ-CELSR1 was done on murine xenografts. The role of the circ-CELSR1/miR149-5p/salt inducible kinase 2 (SIK2) axis as an essential regulator in drug resistance was proven [99].

Three other studies affirmed a high expression of circRNAs in PTX-resistant cells and tissues in OC patients [100-102]. These circRNAs, has-circ-0000714, circ-TNPO3 and circ-NRIP1, perform their functions as oncogenes in cells or tissues by sponging miRNAs and affecting molecules or signaling pathways. Hsa-circ-0000714 targets the CDK6/RB signaling pathway through regulation of RAB17. It acts as a miR-370-3p 
sponge, authorizing its regulation of RAB17 expression. Finally, these functions cause an increase in malignancy due to PTX-resistance in OC cells [100]. Similarly, circ-TNPO3 (has-circ-0001741) sponges miR-1299 and plays fundamental roles in the chemoresistance and tumorigenesis of OC through upregulation of NEK2 expression [101].

The findings of $\mathrm{Li}$ et al. provide novel information for overcoming chemotherapy resistance in OC. They confirmed the inhibitory mechanism of miR-211-5p against drug resistance in PTX-resistant OC cells. However, circ-NRIP1 hinders this action by sponging miR-211-5p and decreasing its expression. Simultaneously, HOXC8 expression increases and leas tumorigenesis [102].

As mentioned above, EOC is the most significant pathological subtype of OC, accounting for more than $90 \%$ of cases. Amongst the subtypes of EOC, SOC (high-grade serous ovarian cancer) accounts for $60-70 \%$ [103]. Some evidence indicates the potential role of circRNAs as serum biomarkers in several cancers, including these [104, 105]. For instance, circSETDB1 is upregulated in the serum and positively correlated with lymph node metastasis and developed clinical-stage in SOC [106]. Many studies have stated that circRNA expression is higher in EOC tissues than in adjacent normal tissues. CircHIPK3 is one of the best examples of this. In 2018, Ning Liu et al. showed that higher circ-HIPK3 expression is associated with poor prognosis of EOC patients, indicating that circ-HIPK3 can act as an important biomarker for prognosis of EOC [32]. Further studies done using RT-qPCR demonstrate the role of circ-FGFR3 as a suitable prognostic biomarker in EOC. Overexpression of circ-FGFR3 through sponging miR-29a-3p and consequently upregulation of E2F1 induced EOC cell EMT in vitro [83]. Circ-Foxp1 is a circulating exosomal RNA that could be a biomarker and potential remedial target for EOC. Its knockdown can decrease cell proliferation and increase drug resistance sensitivity [107].

\section{CircRNAs as a tumor suppressor}

There is a group of circRNAs that play inhibitory roles in OC tumorigenesis and thus have tumor-suppressive effects. Cancer cells have the ability to avoid anti-growth signals via suppression of the expression of tumor suppressor genes. The anti-growth signals are key through arresting of the cell cycle. These circRNAs, like oncogenic ones, sponge miRNA to manage the malignancy of OC cells. CDR1as may be the best example of a tumor-suppressive circRNA [108, 109]. Its overexpression inhibits the proliferation, migration and invasion of OC cells. The mechanism involves miR-135B-5P. Silencing CDR1as increases the expression of miR-135B-5P, which in turn reduces the expression of hypoxia-inducible factor 1-alpha inhibitor (HIF1AN), thus increasing proliferation capacity in OC cells [108]. A separate study conducted on the suppressor effect of CDR1as demonstrated that its expression in OC cisplatin-resistant cells was severely downregulated [109]. The authors found that increasing Cdr1as could promote the sensitivity of OC cells to cisplatin, with the effect occurring through regulation of the miR1270/SCAI axis.

Circ-BNC2， circ-EXOC6B， circ-FAM13B， circ-N4BP2L2， circ-RHOBTB3， circCELSR1, circ-ITCH and circ1656 are involved in EOC in a tumor-suppressive capacity. They could also potentially act as novel diagnostic biomarkers [110-112]. Circ-BNC2 is already used as a diagnostic marker in patients with OC. It is downregulated in both 
serum and tissues [113]. Circ-EXOC6B and circ-N4BP2L2 are known as potential prognostic biomarkers in EOC. CircEXOC6B affects drug resistance, inhibiting the PTXresistance and progression of OC cells by detaching miR-376c-3p, which increases the FOXO3 level [114]. Wang et al. also confirmed circ-EXOC6B's inhibitory role in the progression of OC, establishing the promotion of proliferation and invasion of OC cells through circEXOC6B downregulation [115].

It has been shown that the expression of Circ-ITCH decreases in EOC cell lines in comparison to normal ones and is associated with tumor size, decreasing FIGO stage, and inhibition of cell proliferation [111]. However, it was also found that overexpression of this circRNA extensively suppresses cell proliferation and apoptosis through an interaction with miR-10a [116]. Another study performed on circ-ITCH found an association with poor prognosis, but the inhibition of tumor progression could be accomplished via the circ-ITCH/miR-145/RASA1 signaling pathway with an increase in the expression of RASA1 in OC cells and tissues in both in vivo and in vitro. Downregulation of circITCH inhibits OC cell growth, migration and invasion [117]. Yan et al. also confirmed circ-ITCH downregulation in OC [118].

Using RT-qPCR, Yalan et al. established that circ-RHOBTB3 downregulation induces OC formation with the inactivation of the PI3K/AKT signaling pathway [119]. Another tumor suppressor circRNA, Circ-9119, was found to inhibit cell viability by influencing the PTEN/AKT signaling pathway through a competitive reaction with miR-21 as a prognostic and therapeutic factor in OC [120].

Circ-ANKRD12 locates in the cytoplasm and is a potential clinical biomarker. It is involved in various functions, including invasion, cell cycle arrest, cancer metabolism alteration, and immune system modulation [121]. The expression of circ-LARP4 significantly decreases in OC tissues and it can act as a potential biomarker for prognosis [122]. Circ-PLEKHM3 is another downregulated circRNA found in OC cells. It sponges miR-9 and inactivates the Wnt/ $\beta$-catenin and AKT signaling pathways, suppressing OC cell growth and migration [123].

Like other tumor suppressor circRNAs, circ-0078607 downregulation leads to OC formation. Zhang et al. indicated that inducing Fas expression via oncogenic miR-518a-5p suppresses OC. This circRNA is suggested as a new effective therapeutic target in OC treatment [124]. Circ-0007874 also provides a new therapeutic approach for OC with its tumor-suppressive potential through regulation of the miR-760/SOCS3 axis [125].

Circ-MTO1/miR-182-5p/KLF15 also inhibits OC progression [126]. Circ-100395 showed downregulation in $\mathrm{OC}$ and poor prognosis value. It inhibits cell proliferation and metastasis of OC cells by regulating the miR-1228/EMT/P53 pathway [127]. Two recent studies on Circ-0007444 and has-Circ-0026123 highlighted their suppressive roles. The circ-0007444/miR-570-3p/PTEN axis can be a candidate for target therapy [120].

\section{CircRNA biogenesis}

In recent years, broad research on circRNA biogenesis has been conducted. At first, it was believed that circRNAs were just a transcriptional derangement from the RNA splicing process, but further study has fully authenticated their strictly regulated biosynthesis. However, that biogenesis is not yet fully elucidated, leaving more space for research. It is currently known that circRNAs are single-stranded, looped RNA molecules that are 
generated from pre-mRNAs via a back-splicing process expressed under particular situations. They principally reside in the cytoplasm where they have various functions associated with binding to other molecules such as proteins and miRNAs [128].

\section{Conclusion}

Mounting evidence shows that circRNAs are dysregulated in cancerous tissues and can intercede in diverse signaling pathways, resulting in tumorigenesis, invasion and metastasis [129]. Impairment of some circRNAs in OC cell lines and tissues increases cancer progression by inducing cell division, migration and invasion [130]. CircRNAs can participate in the regulation of tumorigenesis in different types of malignancies using their regulatory structures. The improved understanding of circRNAs helps elucidate the molecular mechanisms involved in OC. Furthermore, because of their high stability and ubiquitously presence in body fluids, including breast milk, saliva, urine and blood, and in membrane vesicles, such as exosomes, circRNAs may serve as promising biomarkers for the early diagnosis and therapeutic achievements in cancer [131].

\section{Outlook}

One of the most important needs in medical science is to have methods for the early detection and non-invasive treatment of cancer. CircRNAs have attracted considerable attention. Thanks to the rapid development in the fields of biotechnology and bioinformatics data analysis, a large number of these RNAs have been identified in different organisms. Due to their unusual expression and their effect on cancer cell growth, proliferation, apoptosis and metastasis, they can be an appropriate option for use as diagnostic biomarkers and therapeutic targets [132, 133]. To the best of our knowledge, the presence of circRNAs in exosomes in cellular communications [134] can be significant for early diagnosis and prognostic determinations [135].

Although sponging miRNAs is a substantial function of circRNAs, many do not have binding sites for miRNAs. Therefore, there may be other means of action besides sponging miRNAs. More studies are needed to elucidate the relationships and pathways relevant for miRNAs, circRNAs and proteins.

Many recent studies into circRNAs and their role in tumor resistance to chemotherapy indicate the involvement of regulatory pathway mechanisms, such as EMT processing, apoptosis, ceRNA regulation and autophagy [136]. Although many advances have been made in the field of circRNAs in OC, especially in the field of drug resistance and chemotherapy resistance, it is currently not possible to apply this knowledge fully in clinical procedures [137]. It is vital to recognize an effective therapeutic target that can tenderize OC to drugs and clarify the molecular pathway of drug resistance in this malignancy. Subsequent findings about circRNAs should also be explored. Some novel technologies, like nanopore sequencing, can potentially gather data on the whole circRNA and be a significant addition to the transcriptome toolbox for mammalian studies [138].

All the descriptions in this paper form just a small part of the capabilities and potential of these unique molecules in the prognosis and diagnosis of OC. Further comprehensive studies are needed to decipher the numerous aspects of circRNA behavior and use them in future clinical procedures. 


\begin{abstract}
Abbreviations
OC: Ovarian cancer; EOC: Epithelial ovarian cancer; HGSC: High-grade serous carcinomas; LGSC: Low-grade serious carcinomas; CircRNAs: Circular RNAs; MiRNA: MicroRNA; NcRNAs: Non-coding RNAs; CeRNA: Competing ENDOGENOUS RNA; Pre-mRNA: Precursor mRNA; AUC: Area under the receiver operating characteristic curve; RT-qPCR: Reverse transcriptasequantitative real-time PCR; FIGO: International Federation of Gynecology and Obstetrics; EMT: Epithelial-mesenchymal transition; CDR1as: Cerebellar degenerative-relate protein-1; FOXM1: Forkhead box M1; CSPP1: Centrosome/spindle poleassociated protein 1; GFRA1: GDNF family receptor alpha 1; EPSTI1: Epithelial stromal interaction 1; IGFBP5: Insulin-like growth factor-binding protein-5; ZEB1: Zinc finger E-box binding homeobox1; HIF1AN: Hypoxia-inducible factor-1 alpha inhibitor; ITCH: Itchy E3 ubiquitin protein ligase; RASA1: RAS P21 protein activator 1; HIPK3: Homeodomain-interacting protein kinase 3; ABC Transporters: The ATP-binding cassette transporters; NOLC1: Nucleolar and coiled-body phosphoprotein 1; CDK1: Cyclin dependent kinase 1; ESRP1: Epithelial splicing regulatory protein 1; RhoA: Ras homolog family member A; ABCB10: ATP binding cassette subfamily B member 10; FAM53B: Family with sequence similarity 53 member B; CELSR1: Cadherin EGF LAG seven-pass G-type receptor 1; PTX- Resistance: Paclitaxel resistance;VPS13C: Vacuolar protein sorting 13 homolog C; PVT1: Plasmacytoma variant translocation 1.
\end{abstract}

\title{
Supplementary Information
}

The online version contains supplementary material available at https://doi.org/10.1186/s11658-021-00284-7.

Additional file 1. PRISMA Checklist

Acknowledgements

Not applicable.

Authors' contributions

ZF and MRA designed the study. ZF drafted the manuscript. FZ, KN-K, DR and FP were involved in data collection. FS and ZF critically revised the manuscript for intellectual content. MRA supervised the study. All listed authors read and approved the final manuscript.

\section{Funding}

This study was funded by Research Center for Evidence-based Medicine at Tabriz University of Medical Sciences, Grant Number (67011)

\section{Availability of data and materials}

The data that support the findings of this study are available on request from the corresponding author. The data are not publicly available due to privacy or ethical restrictions.

\section{Declarations}

Ethics approval and consent to participate

Not applicable.

\section{Consent for publication}

Not applicable.

\section{Competing interests}

The authors declare no conflict of interest.

\section{Author details}

${ }^{1}$ Department of Medical Genetics, Faculty of Medicine, Tabriz University of Medical Sciences, Tabriz, Iran. ${ }^{2}$ Pharmaceutical Sciences Research Center, Ardabil University of Medical Science, Ardabil, Iran. ${ }^{3}$ Research Center for Evidence-Based Medicine, Tabriz University of Medical Science, Tabriz, Iran. ${ }^{4}$ Department of Immunology and Allergy, Academic Center for Education, Culture, and Research, Tehran, Iran.

Received: 23 May 2021 Accepted: 10 September 2021

Published online: 23 September 2021

\section{References}

1. Torre LA, Trabert B, DeSantis CE, Miller KD, Samimi G, Runowicz CD, et al. Ovarian cancer statistics, 2018. CA. 2018;68(4):284-96.

2. Ovary, Source: Globocan. https://gco.iarc.fr/today/data/factsheets/cancers/25-Ovary-fact-sheet.pdf.

3. Lheureux S, Gourley C, Vergote I, Oza AM. Epithelial ovarian cancer. Lancet. 2019;393(10177):1240-53.

4. Wentzensen N, Poole EM, Trabert B, White E, Arslan AA, Patel AV, et al. Ovarian cancer risk factors by histologic subtype: an analysis from the ovarian cancer cohort consortium. J Clin Oncol. 2016;34(24):2888.

5. Prat J. New insights into ovarian cancer pathology. Ann Oncol. 2012;23:x111-7.

6. Consortium EP. An integrated encyclopedia of DNA elements in the human genome. Nature. 2012;489(7414):57.

7. Davalos V, Esteller M. Disruption of long noncoding RNAs targets cancer hallmark pathways in lung tumorigenesis Can Res. 2019;79(12):3028-30. 
8. Romano G, Saviana M, Le P, Li H, Micalo L, Nigita G, et al. Non-coding RNA editing in cancer pathogenesis. Cancers. 2020;12(7):1845.

9. Sanger HL, Klotz G, Riesner D, Gross HJ, Kleinschmidt AK. Viroids are single-stranded covalently closed circular RNA molecules existing as highly base-paired rod-like structures. Proc Natl Acad Sci. 1976;73(11):3852-6.

10. Hsu M-T, Coca-Prados M. Electron microscopic evidence for the circular form of RNA in the cytoplasm of eukaryotic cells. Nature. 1979;280(5720):339-40.

11. Chen X, Han P, Zhou T, Guo X, Song X, Li Y. circRNADb: a comprehensive database for human circular RNAs with protein-coding annotations. Sci Rep. 2016;6(1):1-6.

12. Shen T, Han M, Wei G, Ni T. An intriguing RNA species_-perspectives of circularized RNA. Protein Cell. 2015;6(12):871-80

13. Guo JU, Agarwal V, Guo H, Bartel DP. Expanded identification and characterization of mammalian circular RNAs. Genome Biol. 2014;15(7):1-14.

14. Ivanov A, Memczak S, Wyler E, Torti F, Porath HT, Orejuela MR, et al. Analysis of intron sequences reveals hallmarks of circular RNA biogenesis in animals. Cell Rep. 2015;10(2):170-7.

15. Kelly S, Greenman C, Cook PR, Papantonis A. Exon skipping is correlated with exon circularization. J Mol Biol. 2015:427(15):2414-7.

16. Wang R, Zhang S, Chen X, Li N, Li J, Jia R, et al. ElF4A3-induced circular RNA MMP9 (circMMP9) acts as a sponge of miR-124 and promotes glioblastoma multiforme cell tumorigenesis. Mol Cancer. 2018;17(1):1-12.

17. Feng Y, Zhang L, Wu J, Khadka B, Fang Z, Gu J, et al. CircRNA circ_0000190 inhibits the progression of multiple myeloma through modulating miR-767-5p/MAPK4 pathway. J Exp Clin Cancer Res. 2019;38(1):1-17.

18. Lu Q, Liu T, Feng H, Yang R, Zhao X, Chen W, et al. Circular RNA circSLC8A1 acts as a sponge of miR-130b/miR-494 in suppressing bladder cancer progression via regulating PTEN. Mol Cancer. 2019:18(1):1-13.

19. Chen N, Zhao G, Yan X, Lv Z, Yin H, Zhang S, et al. A novel FLI1 exonic circular RNA promotes metastasis in breast cancer by coordinately regulating TET1 and DNMT1. Genome Biol. 2018;19(1):1-14.

20. Jiang L-h, Sun D-w, Hou J-c, Ji Z-I. CircRNA: a novel type of biomarker for cancer. Breast Cancer. 2018;25(1):1-7.

21. Peters MDJ, Marnie C, Tricco AC, Pollock D, Munn Z, Alexander L, et al. Updated methodological guidance for the conduct of scoping reviews. JBI Evid Synth. 2020;18(10):2119-26.

22. Preferred Reporting Items for Systematic reviews and Meta-Analyses extension for Scoping Reviews (PRISMA-ScR) Checklist.

23. Hansen TB, Jensen TI, Clausen BH, Bramsen JB, Finsen B, Damgaard CK, et al. Natural RNA circles function as efficient microRNA sponges. Nature. 2013;495(7441):384-8.

24. Ahmed I, Karedath T, Al-Dasim FM, Malek JA. Identification of human genetic variants controlling circular RNA expression. RNA. 2019;25(12):1765-78.

25. Yang X, Mei J, Wang H, Gu D, Ding J, Liu C. The emerging roles of circular RNAs in ovarian cancer. Cancer Cell Int. 2020;20(1):1-11.

26. Jeck WR, Sorrentino JA, Wang K, Slevin MK, Burd CE, Liu J, et al. Circular RNAs are abundant, conserved, and associated with ALU repeats. RNA. 2013;19(2):141-57.

27. Wang PL, Bao Y, Yee MC, Barrett SP, Hogan GJ, Olsen MN, et al. Circular RNA is expressed across the eukaryotic tree of life. PLoS ONE. 2014;9(6):e90859.

28. Lai Z, Yang Y, Yan Y, Li T, Li Y, Wang Z, et al. Analysis of co-expression networks for circular RNAs and mRNAs reveals that circular RNAs hsa_circ_0047905, hsa_circ_0138960 and has-circRNA7690-15 are candidate oncogenes in gastric cancer. Cell Cycle. 2017;16(23):2301-11.

29. Zhao Z-J, Shen J. Circular RNA participates in the carcinogenesis and the malignant behavior of cancer. RNA Biol. 2017:14(5):514-21.

30. Kristensen LS, Hansen TB, Venø MT, Kjems J. Circular RNAs in cancer: opportunities and challenges in the field. Oncogene. 2018:37:555-65.

31. Ding Q, Dong S, Wang R, Zhang K, Wang H, Zhou X, et al. A nine-gene signature related to tumor microenvironment predicts overall survival with ovarian cancer. Aging (Albany NY). 2020;12(6):4879.

32. Teng $F$, Xu J, Zhang M, Liu S, Gu Y, Zhang M, et al. Comprehensive circular RNA expression profiles and the tumorsuppressive function of circHIPK3 in ovarian cancer. Int J Biochem Cell Biol. 2019;112:8-17.

33. Jayson GC, Kohn EC, Kitchener HC, Ledermann JA. Ovarian cancer. The Lancet. 2014;384(9951):1376-88

34. Visvanathan K, Wang T-L, Shih I-M. Precancerous lesions of ovarian cancer-a US perspective. Oxford: Oxford University Press; 2018

35. Carlson KJ, Skates SJ, Singer DE. Screening for ovarian cancer. Ann Intern Med. 1994;121(2):124-32.

36. McMullen M, Karakasis K, Rottapel R, Oza AM. Advances in ovarian cancer, from biology to treatment. Nat Cancer. 2021;2(1):6-8.

37. Meng S, Zhou H, Feng Z, Xu Z, Tang Y, Li P, et al. CircRNA: functions and properties of a novel potential biomarker for cancer. Mol Cancer. 2017;16(1):1-8.

38. Wang M, Xie F, Lin J, Zhao Y, Zhang Q, Liao Z, et al. Diagnostic and prognostic value of circulating CircRNAs in cancer. Front Med. 2021;8:231

39. Chen L, Shan G. CircRNA in cancer: Fundamental mechanism and clinical potential. Cancer Lett. 2021;505:49-57.

40. Tang Y, Jiang M, Jiang H-M, Ye ZJ, Huang Y-S, Li X-S, et al. The roles of circRNAs in liver cancer immunity. Front Oncol. 2021;10:3120

41. Yang L, Zou X, Zou J, Zhang G. Functions of circular RNAs in bladder, prostate and renal cell cancer. Mol Med Rep. 2021;23(5):1-12.

42. Gao C, Xu YJ, Qi L, Bao YF, Zhang L, Zheng L. CircRNA VIM silence synergizes with sevoflurane to inhibit immune escape and multiple oncogenic activities of esophageal cancer by simultaneously regulating miR-124/PD-L1 axis. Cell Biol Toxicol. 2021:18:1-21.

43. Tang L, Jiang B, Zhu H, Gao T, Zhou Y, Gong F, et al. The biogenesis and functions of circRNAs and their roles in breast cancer. Front Oncol. 2021;11:175. 
44. Ma S, Kong S, Gu X, Xu Y, Tao M, Shen L, et al. As a biomarker for gastric cancer, circPTPN22 regulates the progression of gastric cancer through the EMT pathway. Cancer Cell Int. 2021;21(1):1-14.

45. Ghafouri-Fard S, Dinger ME, Maleki P, Taheri M, Hajiesmaeili M. Emerging role of circular RNAs in the pathobiology of lung cancer. Biomed Pharmacother. 2021;141:111805.

46. Tang X, Ren H, Guo M, Qian J, Yang Y, Gu C. Review on circular RNAs and new insights into their roles in cancer. Comput Struct Biotechnol J. 2021;19:910.

47. Ruan H, Xiang Y, Ko J, Li S, Jing Y, Zhu X, et al. Comprehensive characterization of circular RNAs in 1000 human cancer cell lines. Genome Med. 2019;11(1):1-14.

48. Huang Y, Zhang C, Xiong J, Ren H. Emerging important roles of circRNAs in human cancer and other diseases. Genes Dis. 2021;8(4):412-23.

49. Jeck WR, Sharpless NE. Detecting and characterizing circular RNAs. Nat Biotechnol. 2014;32(5):453-61.

50. Verduci L, Tarcitano E, Strano S, Yarden Y, Blandino G. CircRNAs: role in human diseases and potential use as biomarkers. Cell Death Dis. 2021;12(5):1-12.

51. Karedath T, Al-Dasim FM, Ahmed I, Al-Qurashi A, Raza A, Andrews SS, et al. Regulation of circular RNA CircNFATC3 in cancer cells alters proliferation, migration, and oxidative phosphorylation. Front Cell Dev Biol. 2021;9:595156.

52. Zhang M, Xia B, Xu Y, Zhang Y, Xu J, Lou G. Circular RNA (hsa_circ_0051240) promotes cell proliferation, migration and invasion in ovarian cancer through miR-637/KLK4 axis. Artif Cells Nanomed Biotechnol. 2019;47(1):1224-33.

53. Xie J, Wang S, Li G, Zhao X, Jiang F, Liu J, et al. circEPSTI1 regulates ovarian cancer progression via decoying miR942. J Cell Mol Med. 2019;23(5):3597-602.

54. Sun Y, Li X, Chen A, Shi W, Wang L, Yi R, et al. circPIP5K1A serves as a competitive endogenous RNA contributing to ovarian cancer progression via regulation of miR-661/IGFBP5 signaling. J Cell Biochem. 2019;120(12):19406-14.

55. Liu J, Yu F, Wang $S$, Zhao X, Jiang F, Xie J, et al. circGFRA1 promotes ovarian cancer progression by sponging miR449a. J Cancer. 2019;10(17):3908.

56. Sheng M, Wei N, Yang H, Yan M, Zhao Q, Jing L. CircRNA UBAP2 promotes the progression of ovarian cancer by sponging microRNA-144. Eur Rev Med Pharmacol Sci. 2019;23(17):7283-94.

57. Xu Q, Deng B, Li M, Chen Y, Zhuan L. circRNA-UBAP2 promotes the proliferation and inhibits apoptosis of ovarian cancer though miR-382-5p/PRPF8 axis. J Ovarian Res. 2020;13(1):1-10.

58. Deng G. High expression of ESRP1 regulated by circ-0005585 promotes cell colonization in ovarian cancer. Cancer Cell Int. 2020;174:1-15.

59. Wang G, Zhang H, Li P. Upregulation of hsa_circRNA_102958 indicates poor prognosis and promotes ovarian cancer progression through miR-1205/SH2D3A axis. Cancer Manage Res. 2020;12:4045.

60. Zhao Y, Hu Y, Shen Q, Chen Q, Zhu X, Jiang S, et al. CircRNA_MYLK promotes malignant progression of ovarian cancer through regulating microRNA-652. Eur Rev Med Pharmacol Sci. 2020;24(10):5281-91.

61. Li Q-H, Liu Y, Chen S, Zong Z-H, Du Y-P, Sheng X-J, et al. circ-CSPP1 promotes proliferation, invasion and migration of ovarian cancer cells by acting as a miR-1236-3p sponge. Biomed Pharmacother. 2019;114:108832.

62. Yang X, Wang J, Li H, Sun Y, Tong X. Downregulation of hsa_circ_0026123 suppresses ovarian cancer cell metastasis and proliferation through the miR-124-3p/EZH2 signaling pathway. Int J Mol Med. 2021;47(2):668-76.

63. Zhao Y, Qin X, Lang Y, Kou D, Shao Z. Circular RNA circ-SMAD7 promoted ovarian cancer cell proliferation and metastasis by suppressing KLF6. Eur Rev Med Pharmacol Sci. 2020;24(14):7563.

64. Zong Z-H, Du Y-P, Guan X, Chen S, Zhao Y. CircWHSC1 promotes ovarian cancer progression by regulating MUC1 and hTERT through sponging miR-145 and miR-1182. J Exp Clin Cancer Res. 2019;38(1):1-10.

65. LiY, Lin S, An N. Hsa_circ_0009910: oncogenic circular RNA targets microRNA-145 in ovarian cancer cells. Cell Cycle. 2020;19(15):1857-68.

66. Bao L, Zhong J, Pang L. Upregulation of circular RNA VPS13C-has-circ-001567 promotes ovarian Cancer cell proliferation and invasion. Cancer Biother Radiopharm. 2019;34(2):110-8.

67. Lu H, Zheng G, Gao X, Chen C, Zhou M, Zhang L. Propofol suppresses cell viability, cell cycle progression and motility and induces cell apoptosis of ovarian cancer cells through suppressing MEK/ERK signaling via targeting circVPS13C/miR-145 axis. J Ovarian Res. 2021;14(1):1-11.

68. Zhang C, Li Y, Zhao W, Liu G, Yang Q. Circ-PGAM1 promotes malignant progression of epithelial ovarian cancer through regulation of the miR-542-3p/CDC5L/PEAK1 pathway. Cancer Med. 2020;9(10):3500-21.

69. Chen J, Li X, Yang L, Li M, Zhang Y, Zhang J. CircASH2L promotes ovarian cancer tumorigenesis, angiogenesis, and lymphangiogenesis by regulating the miR-665/NEGFA axis as a competing endogenous RNA. Front Cell Dev Biol. 2020;8:1405.

70. Deng G, Zhou X, Chen L, Yao Y, Li J, Zhang Y, et al. High expression of ESRP1 regulated by circ-0005585 promotes cell colonization in ovarian cancer. Cancer Cell Int. 2020;20:1-15.

71. Pei C, Wang H, Shi C, Zhang C, Wang M. CircRNA hsa_circ_0013958 may contribute to the development of ovarian cancer by affecting epithelial-mesenchymal transition and apoptotic signaling pathways. J Clin Lab Anal. 2020;34(7):e23292.

72. Guan X, Zong Z-H, Liu Y, Chen S, Wang L-L, Zhao Y. circPUM1 promotes tumorigenesis and progression of ovarian cancer by sponging miR-615-5p and miR-6753-5p. Mol Therapy-Nucleic Acids. 2019;18:882-92.

73. Wang LL, Zong ZH, Liu Y, Guan X, Chen S, Zhao Y. CircRhoC promotes tumorigenicity and progression in ovarian cancer by functioning as a miR-302e sponge to positively regulate VEGFA. J Cell Mol Med. 2019;23(12):8472-81.

74. Zhang F, XuY, Ye W, Jiang J, Wu C. Circular RNA S-7 promotes ovarian cancer EMT via sponging miR-641 to upregulate ZEB1 and MDM2. Biosci Rep. 2020;40(7):1.

75. Chen S, Wu W, Li Q-H, Xie B-M, Shen F, Du Y-P, et al. Circ-NOLC1 promotes epithelial ovarian cancer tumorigenesis and progression by binding ESRP1 and modulating CDK1 and RhoA expression. Cell Death Discov. 2021;7(1):1-14

76. Gan X, Zhu H, Jiang X, Obiegbusi SC, Yong M, Long X, et al. CircMUC16 promotes autophagy of epithelial ovarian cancer via interaction with ATG13 and miR-199a. Mol Cancer. 2020;19(1):1-13.

77. Sun D, Liu J, Zhou L. Upregulation of circular RNA circ-FAM53B predicts adverse prognosis and accelerates the progression of ovarian cancer via the miR-646/NAMP2 and miR-647/MDM2 signaling pathways. Oncol Rep. 2019;42(6):2728-37. 
78. Ma R, Ye X, Cheng H, Cui H, Chang X. Tumor-derived exosomal circRNA051239 promotes proliferation and migration of epithelial ovarian cancer. Am J Transl Res. 2021;13(3):1125.

79. Chen Y, Ye X, Xia X, Lin X. Circular RNA ABCB10 correlates with advanced clinicopathological features and unfavorable survival, and promotes cell proliferation while reduces cell apoptosis in epithelial ovarian cancer. Cancer Biomark. 2019;26(2):151-61.

80. Ding J, Wang Q, Guo N, Wang H, Chen H, Ni G, et al. CircRNA circ_0072995 promotes the progression of epithelial ovarian cancer by modulating miR-147a/CDK6 axis. Aging (Albany NY). 2020;12(17):17209.

81. Yong M, Hu J, Zhu H, Jiang X, Gan X, Hu L. Circ-EEF2 facilitated autophagy via interaction with mir-6881-3p and ANXA2 in EOC. Am J Cancer Res. 2021;11(4):1795.

82. Zhang Z, Zhu H, Hu J. CircRAB1 1FIP1 promoted autophagy flux of ovarian cancer through DSC1 and miR-129. Cell Death Dis. 2021;12(2):1-12.

83. Zhou J, Dong Z-N, Qiu B-Q, Hu M, Liang X-Q, Dai X, et al. CircRNA FGFR3 induces epithelial-mesenchymal transition of ovarian cancer by regulating miR-29a-3p/E2F1 axis. Aging (Albany NY). 2020;12(14):14080.

84. Lin X, Chen Y, Ye X, Xia X. Circular RNA ABCB10 promotes cell proliferation and invasion, but inhibits apoptosis via regulating the microRNA-1271-mediated Capn4/Wnt/ $\beta$-catenin signaling pathway in epithelial ovarian cancer. Mol Med Rep. 2021;23(5):1-9.

85. Sun X, Luo L, Gao Y. Circular RNA PVT1 enhances cell proliferation but inhibits apoptosis through sponging microRNA-149 in epithelial ovarian cancer. J Obst Gynaecol Res. 2020;46(4):625-35.

86. Li M, Chi C, Zhou L, Chen Y, Tang X. Circular PVT1 regulates cell proliferation and invasion via miR-149-5p/FOXM1 axis in ovarian cancer. J Cancer. 2021;12(2):611.

87. Wang J, Wu A, Yang B, Zhu X, Teng Y, Ai Z. Profiling and bioinformatics analyses reveal differential circular RNA expression in ovarian cancer. Gene. 2020;724:144150.

88. Du Z, Wang L, Xia Y. Circ_0015756 promotes the progression of ovarian cancer by regulating miR-942-5p/CUL4B pathway. Cancer Cell Int. 2020;20(1):1-13.

89. Xie W, Liu L, He C, Zhao M, Ni R, Zhang Z, et al. Circ _ 0002711 knockdown suppresses cell growth and aerobic glycolysis by modulating miR-1244/ROCK1 axis in ovarian cancer. J Biosci. 2021;46(1):1-11.

90. Zhang C, Liu W, Li F, Feng Y, Li Y, Wang J. Hsa_circ_0015326 promotes the proliferation, invasion and migration of ovarian cancer through miR-127-3p/MYB. Cancer Manag Res. 2021;13:2265.

91. Wang X, Yao Y, Jin M. Circ-0001068 is a novel biomarker for ovarian cancer and inducer of PD1 expression in T cells. Aging (Albany NY). 2020;12(19):19095.

92. Hou W, Zhang Y. Circ_0025033 promotes the progression of ovarian cancer by activating the expression of LSM4 via targeting miR-184. Pathol Res Pract. 2021;217:153275.

93. Cheng H, Wang N, Tian J, Li Y, Ren L, Shi Z. Circular RNA Circ 0025033 promotes the evolvement of ovarian cancer through the regulation of miR-330-5p/KLK4 axis. Cancer Manag Res. 2020;12:2753.

94. Sheng S, Hu Y, Yu F, Tong W, Wang S, Cai Y, et al. circKIF4A sponges miR-127 to promote ovarian cancer progression. Aging (Albany NY). 2020;12(18):17921.

95. Xu F, Ni M, Li J, Cheng J, Zhao H, Zhao J, et al. Circ0004390 promotes cell proliferation through sponging miR-198 in ovarian cancer. Biochem Biophys Res Commun. 2020;526(1):14-20.

96. Cui C, Yang J, Li X, Liu D, Fu L, Wang X. Functions and mechanisms of circular RNAs in cancer radiotherapy and chemotherapy resistance. Mol Cancer. 2020;19(1):58.

97. Chen Q, Zhang J, He Y, Wang Y. hsa_circ_0061140 knockdown reverses FOXM1-mediated cell growth and metastasis in ovarian cancer through miR-370 sponge activity. Mol Therapy. 2018;13:55-63.

98. Zhang S, Cheng J, Quan C, Wen H, Feng Z, Hu Q, et al. circCELSR1 (hsa_circ_0063809) contributes to paclitaxel resistance of ovarian cancer cells by regulating FOXR2 expression via miR-1252. Mol Therapy. 2020;19:718-30.

99. Wei S, Qi L, Wang L. Overexpression of circ_CELSR1 facilitates paclitaxel resistance of ovarian cancer by regulating miR-149-5p/SIK2 axis. Anticancer Drugs. 2021;32(5):496-507.

100. Guo M, Li S, Zhao X, Yuan Y, Zhang B, Guan Y. Knockdown of circular RNA Hsa_circ_0000714 can regulate RAB17 by sponging miR-370-3p to reduce paclitaxel resistance of ovarian cancer through CDK6/RB pathway. Onco Targets Ther. 2020;13:13211.

101. Xia B, Zhao Z, Wu Y, Wang Y, Zhao Y, Wang J. Circular RNA circTNPO3 regulates paclitaxel resistance of ovarian cancer cells by miR-1299/NEK2 signaling pathway. Mol Ther. 2020;21:780-91.

102. Li M, Cai J, Han X, Ren Y. Downregulation of circNRIP1 suppresses the paclitaxel resistance of ovarian cancer via regulating the miR-211-5p/HOXC8 axis. Cancer Manag Res. 2020;12:9159.

103. Bachmayr-Heyda AAK, Sukhbaatar N, Aust S, Deycmar S, Reiner AT, Polterauer S, Dekan S, Pils D. Small RNAs and the competing endogenous RNA network in high grade serous ovarian cancer tumor spread. Oncotargets. 2016;7:39640-53.

104. Vo JN, Cieslik M, Zhang Y, Shukla S, Xiao L, Zhang Y, et al. The landscape of circular RNA in cancer. Cell. 2019;176(4):869-81.

105. Vea A, Llorente-Cortes V, de Gonzalo-Calvo D. Circular RNAs in blood. Circ RNAs. 2018;1:119-30.

106. Wang W, Wang J, Zhang X, Liu G. Serum cirCSETDB1 is a promising biomarker for predicting response to platinum-taxane-combined chemotherapy and relapse in high-grade serous ovarian cancer. Onco Targets Ther. 2019;12:7451.

107. Luo Y, Gui R. Circulating exosomal circFoxp1 confers cisplatin resistance in epithelial ovarian cancer cells. J Gynecol Oncol. 2020;31(5):1.

108. Chen H, Mao M, Jiang J, Zhu D, Li P. Circular RNA CDR1as acts as a sponge of miR-135b-5p to suppress ovarian cancer progression. Onco Targets Ther. 2019;12:3869.

109. Zhao Z, Ji M, Wang Q, He N, Li Y. Circular RNA Cdr1as upregulates SCAl to suppress cisplatin resistance in ovarian cancer via miR-1270 suppression. Mol Ther. 2019;18:24-33.

110. Ning L, Long B, Zhang W, Yu M, Wang S, Cao D, et al. Circular RNA profiling reveals circEXOC6B and circN4BP2L2 as novel prognostic biomarkers in epithelial ovarian cancer. Int J Oncol. 2018;53(6):2637-46. 
111. Luo L, Gao Y, Sun X. Circ-ITCH correlates with small tumor size, decreased FIGO stage and prolonged overall survival, and it inhibits cells proliferation while promotes cells apoptosis in epithelial ovarian cancer. Cancer Biomark. 2018;23(4):505-13.

112. Gao Y, Zhang C, Liu Y, Wang M. Circular RNA profiling reveals circRNA1656 as a novel biomarker in high grade serous ovarian cancer. Biosci Trends. 2019;13(2):204-11.

113. Hu Y, Zhu Y, Zhang W, Lang J, Ning L. Utility of plasma circBNC2 as a diagnostic biomarker in epithelial ovarian cancer. Onco Targets Ther. 2019;12:9715.

114. Zheng Y, Li Z, Yang S, Wang Y, Luan Z. CircEXOC6B suppresses the proliferation and motility and sensitizes ovarian cancer cells to paclitaxel through miR-376c-3p/FOXO3 axis. Cancer Biother Radiopharm. 2020. https://doi.org/10. 1089/cbr.2020.3739.

115. Wang Z, Zhang W, Fang J, Xie P, Miao M, Yang H. Circular RNA circEXOC6B inhibits the progression of ovarian cancer by sponging miR-421 and regulating RUS1 expression. Onco Targets Ther. 2020;13:8233.

116. Luo L, Gao Y, Sun X. Circular RNA ITCH suppresses proliferation and promotes apoptosis in human epithelial ovarian cancer cells by sponging miR-10a-alpha. Eur Rev Med Pharmacol Sci. 2018;22(23):8119-26.

117. Hu J, Wang L, Chen J, Gao H, Zhao W, Huang Y, et al. The circular RNA circ-ITCH suppresses ovarian carcinoma progression through targeting miR-145/RASA1 signaling. Biochem Biophys Res Commun. 2018;505(1):222-8.

118. Yan H, Xiang H, Sun B, Feng F, Chen P. Circular RNA-ITCH inhibits the proliferation of ovarian carcinoma by downregulating IncRNA HULC. Reprod Sci. 2020;27(1):375-9.

119. Yalan S, Yanfang L, He C, Yujie T. Circular RNA circRHOBTB3 inhibits ovarian cancer progression through PI3K/AKT signaling pathway. Panminerva Med. 2020. https://doi.org/10.23736/S0031-0808.20.03957-9.

120. Gong J, Xu X, Zhang X, Zhou Y. Circular RNA-9119 suppresses in ovarian cancer cell viability via targeting the microRNA-21-5p-PTEN-Akt pathway. Aging (Albany NY). 2020;12(14):14314.

121. Karedath T, Ahmed I, Al Ameri W, Al-Dasim FM, Andrews SS, Samuel S, et al. Silencing of ANKRD12 circRNA induces molecular and functional changes associated with invasive phenotypes. BMC Cancer. 2019;19(1):1-17.

122. Zou T, Wang P, Gao Y, Liang W. Circular RNA_LARP4 is lower expressed and serves as a potential biomarker of ovarian cancer prognosis. Eur Rev Med Pharmacol Sci. 2018;22(21):7178-82.

123. Zhang L, Zhou Q, Qiu Q, Hou L, Wu M, Li J, et al. CircPLEKHM3 acts as a tumor suppressor through regulation of the miR-9/BRCA1/DNAJB6/KLF4/AKT1 axis in ovarian cancer. Mol Cancer. 2019;18(1):1-19.

124. Zhang N, Jin Y, Hu Q, Cheng S, Wang C, Yang Z, et al. Circular RNA hsa_circ_0078607 suppresses ovarian cancer progression by regulating miR-518a-5p/Fas signaling pathway. J Ovarian Res. 2020;13:1-10.

125. Li L, Yu P, Zhang P, Wu H, Chen Q, Li S, et al. Upregulation of hsa_circ_0007874 suppresses the progression of ovarian cancer by regulating the miR-760/SOCS3 pathway. Cancer Med. 2020;9(7):2491-9.

126. Wang N, Cao Q-X, Tian J, Ren L, Cheng H-L, Yang S-Q. Circular RNA MTO1 inhibits the proliferation and invasion of ovarian cancer cells through the miR-182-5p/KLF15 axis. Cell Transpl. 2020;29:0963689720943613.

127. Li X, Lin S, Mo Z, Jiang J, Tang H, Wu C, et al. CircRNA_100395 inhibits cell proliferation and metastasis in ovarian cancer via regulating miR-1228/p53/epithelial-mesenchymal transition (EMT) axis. J Cancer. 2020;11 (3):599.

128. Kristensen LS, Ebbesen KK, Sokol M, Jakobsen T, Korsgaard U, Eriksen AC, et al. Spatial expression analyses of the putative oncogene ciRS-7 in cancer reshape the microRNA sponge theory. Nat Commun. 2020;1 (1):1-12.

129. Dong $\mathrm{P}, \mathrm{Xu} \mathrm{D}$, Xiong $Y$, Yue J, Ihira K, Konno Y, et al. The expression, functions and mechanisms of circular RNAs in gynecological cancers. Cancers. 2020;12(6):1472.

130. Memczak S, Papavasileiou P, Peters O, Rajewsky N. Identification and characterization of circular RNAs as a new class of putative biomarkers in human blood. PLoS ONE. 2015;10(10):e0141214

131. Chen L-L. The expanding regulatory mechanisms and cellular functions of circular RNAs. Nat Rev Mol Cell Biol. 2020;21(8):475-90.

132. Cheng D, Wang J, Dong Z, Li X. Cancer-related circular RNA: diverse biological functions. Cancer Cell Int. 2021:21(1):1-16

133. Yu T, Wang Y, Fan Y, Fang N, Wang T, Xu T, et al. CircRNAs in cancer metabolism: a review. J Hematol Oncol. 2019;12(1):1-10

134. Li X, Wang X. The emerging roles and therapeutic potential of exosomes in epithelial ovarian cancer. Mol Cancer. 2017;16(1):1-10

135. Li J, Li Z, Jiang P, Peng M, Zhang X, Chen K, et al. Circular RNA IARS (circ-IARS) secreted by pancreatic cancer cells and located within exosomes regulates endothelial monolayer permeability to promote tumor metastasis. J Exp Clin Cancer Res. 2018;37(1):1-16.

136. Hua X, Sun Y, Chen J, Wu Y, Sha J, Han S, et al. Circular RNAs in drug resistant tumors. Biomed Pharmacother. 2019;118:109233.

137. Sheng R, Li X, Wang Z, Wang X. Circular RNAs and their emerging roles as diagnostic and prognostic biomarkers in ovarian cancer. Cancer Lett. 2020:473:139-47.

138. Soneson C, Yao Y, Bratus-Neuenschwander A, Patrignani A, Robinson MD, Hussain S. A comprehensive examination of Nanopore native RNA sequencing for characterization of complex transcriptomes. Nat Commun. 2019;10(1):1-14.

139. An Q, LiU T, Wang M, Yang Y, Zhang Z, Lin Z, Yang B. circKRT7-miR-29a-3p-COL1A1 axis promotes ovarian cancer cell progression. Onco Targets Ther. 2020;13:8963-8976.

140. Wu X, Liu D, Wang S, Liu J. Circ_0007444 inhibits the progression of ovarian cancer via mediating the miR-570-3p/ PTEN axis. Onco Targets Ther. 2021;14:97-110. https://doi.org/10.2147/OTT.S266186.

\section{Publisher's Note}

Springer Nature remains neutral with regard to jurisdictional claims in published maps and institutional affiliations. 